\title{
Type 2 diabetes and pre-diabetes mellitus: a systematic review and meta-analysis of prevalence studies in women of childbearing age in the Middle East and North Africa, 2000-2018
}

\author{
Rami H. Al-Rifai ${ }^{*}$ (D), Maria Majeed ${ }^{1}$, Maryam A. Qambar², Ayesha Ibrahim², Khawla M. AlYammahi and Faisal Aziz
}

\begin{abstract}
Background: Investing in women's health is an inevitable investment in our future. We systematically reviewed the available evidence and summarized the weighted prevalence of type 2 diabetes (T2DM) and pre-diabetes mellitus (pre-DM) in women of childbearing age (15-49years) in the Middle East and North African (MENA) region.

Methods: We comprehensively searched six electronic databases to retrieve published literature and prevalence studies on T2DM and pre-DM in women of childbearing age in the MENA. Retrieved citations were screened and data were extracted by at least two independent reviewers. Weighted T2DM and pre-DM prevalence was estimated using the random-effects model.

Results: Of the 10,010 screened citations, 48 research reports were eligible. Respectively, 46 and 24 research reports on T2DM and pre-DM prevalence estimates, from 14 and 10 countries, were included. Overall, the weighted T2DM and pre-DM prevalence in 14 and 10 MENA countries, respectively, were $7.5 \%$ (95\% confidence interval [CI], 6.1-9.0) and $7.6 \%(95 \% \mathrm{Cl}, 5.2-10.4)$. In women sampled from general populations, T2DM prevalence ranged from 0.0 to 35.2\% (pooled, 7.7\%; 95\% Cl, 6.1-9.4\%) and pre-DM prevalence ranged from 0.0 to $40.0 \%$ (pooled, $7.9 \%$; $95 \% \mathrm{Cl}, 5.3-$ 11.0\%). T2DM was more common in the Fertile Crescent countries $(10.7 \%, 95 \% \mathrm{Cl}, 5.2-17.7 \%)$, followed by the Arab Peninsula countries $(7.6 \%, 95 \% \mathrm{Cl}, 5.9-9.5 \%)$ and North African countries and Iran (6.5\%, 95\% Cl, 4.3-9.1\%). Pre-DM prevalence was highest in the Fertile Crescent countries $(22.7 \%, 95 \% \mathrm{Cl}, 14.2-32.4 \%)$, followed by the Arab Peninsula countries $(8.6 \%, 95 \% \mathrm{Cl}, 5.5-12.1 \%)$ and North Africa and Iran $(3.3 \%, 95 \% \mathrm{Cl}, 1.0-6.7 \%)$.

Conclusions: T2DM and pre-DM are common in women of childbearing age in MENA countries. The high DM burden in this vital population group could lead to adverse pregnancy outcomes and acceleration of the intergenerational risk of DM. Our review presented data and highlighted gaps in the evidence of the DM burden in women of childbearing age, to inform policy-makers and researchers.
\end{abstract}

Systematic review registration: PROSPERO CRD42017069231

Keywords: Type 2 diabetes, Pre-diabetes mellitus, Women of childbearing age

\footnotetext{
*Correspondence: rrifai@uaeu.ac.ae

'Institute of Public Health, College of Medicine and Health Sciences, United

Arab Emirates University, P.O. Box 15551, Al Ain, United Arab Emirates

Full list of author information is available at the end of the article
}

(c) The Author(s). 2019 Open Access This article is distributed under the terms of the Creative Commons Attribution 4.0 International License (http://creativecommons.org/licenses/by/4.0/), which permits unrestricted use, distribution, and reproduction in any medium, provided you give appropriate credit to the original author(s) and the source, provide a link to the Creative Commons license, and indicate if changes were made. The Creative Commons Public Domain Dedication waiver (http://creativecommons.org/publicdomain/zero/1.0/) applies to the data made available in this article, unless otherwise stated. 


\section{Background}

The global burden of type 2 diabetes mellitus (T2DM) is rapidly increasing, affecting individuals of all ages. The global T2DM prevalence nearly doubled in the adult population over the past decade from $4.7 \%$ in 1980 to $8.5 \%$ in 2014 [1]. The global burden of T2DM in people 20-79 years is further projected to increase to 629 million in 2045 compared to 425 million in 2017 [1]. Lowand middle-income countries will be the most affected with the rise in the burden of T2DM. For the period between 2017 and 2045, the projected increase in the prevalence of T2DM in the Middle East and North Africa (MENA) region is $110 \%$ compared to $16 \%$ in Europe, 35\% in North Africa and the Caribbean, and 62\% in South and Central America [1]. Pre-diabetes (pre-DM) or intermediate hyperglycaemia is defined as blood glucose levels above the normal range, but lower than DM thresholds [1]. The burden of pre-DM is increasing worldwide. By 2045, the number of people aged between 20 and 79 years old with pre-DM is projected to increase to 587 million (8.3\% of the adult population) compared to 352.1 million people worldwide in 2017 (i.e., 7.3\% of the adult population of adults aged 20 to 79 years) [1]. About three quarters (72.3\%) of people with pre-DM live in low- and middle-income countries [1].

Pre-DM or T2DM are associated with various unfavorable health outcomes. People with pre-DM are at high risk of developing T2DM [1]. Annually, it is estimated that $5-10 \%$ of people with pre-DM will develop T2DM $[2,3]$. Pre-DM and T2DM are also associated with early onset of nephropathy and chronic kidney disease [4-7], diabetic retinopathy $[6,8,9]$, and increased risk of macrovascular disease $[10,11]$. T2DM is also reported to increase the risk of developing active [12] and latent tuberculosis [13]. The rising levels of different modifiable key risk factors, mainly body overweight and obesity, driven by key changes in lifestyle, are the attributes behind the continued burgeoning epidemics of pre-DM and T2DM [14-16]. Women of childbearing age (15-49 years) [17] are also affected by the global rise in pre-DM and T2DM epidemics. Rising blood glucose levels in women of childbearing age has pre-gestational, gestational, and postpartum consequences, including increased intergenerational risk of DM [18].

The total population in 20 countries (Algeria, Bahrain, Djibouti, Egypt, Iran, Iraq, Jordan, Kuwait, Lebanon, Libya, Malta, Morocco, Oman, Palestine, Qatar, Saudi Arabia, Syria, Tunisia, the United Arab Emirates, and Yemen) in the Middle East and North Africa region comprises almost $6.7 \%$ ( 421 million people) of the world's population, with about 200 million females as of July 1, 2015 [19]. In adults $\geq 18$ years, T2DM prevalence rose sharply by 2.3 times in each of the Eastern Mediterranean regions and the African region, between 1980 and 2014 [20]. This sharp increase in these two regions is higher than that reported in the region of the Americas (1.7 times), the European region (1.4 times), and the Western Pacific Region (1.9 times) [20].

Key pre-DM and T2DM risk factors, body overweight and obesity, are highly prevalent in people in the MENA countries. In 2013, the age-standardized prevalence of overweight and obesity among women $\geq 20$ years was $65.5 \%$ (obese $33.9 \%$ ) [21]. The high burden of overweight and obesity in several MENA countries attributed to the interrelated economic, dietary, lifestyle behavioral factors. The nutrition transitions and changes in the food consumption habits were supported by the witnessed economic development in most of the MENA countries. For instance, in the past five decades, the economic development in the Arab Gulf countries linked to the discovery of oil and gas reserves led to changes in eating habits towards the consumption of foods rich in fat and calories as well as increasing behavioral habits towards a sedentary lifestyle $[22,23]$. This is particularly true with the significant shift from the consumption of traditional low-fat food to fat-rich foods, as well as with a major change from an agricultural lifestyle to an urbanized lifestyle that is often accompanied by decreased levels of physical activity. The urbanized lifestyle increases exposure to fast foods through the high penetration of fast food restaurants serving fat-rich foods, the reliance on automobiles for transport, and the increasing penetration of cell phones, all of which facilitate low levels of physical activity. Globally, physical inactivity is estimated to cause around $27 \%$ of diabetes cases [24]. In eight Arab countries, based on national samples, low levels of physical activity in adults ranged from $32.1 \%$ of the population in Egypt in 2011-2012 to as high as 67\% of the population in Saudi Arabia in 2005 [25]. Furthermore, fruit and vegetable consumption is inversely associated with weight gain [26]. Studies indicated a low intake of fruit and vegetables in some of the MENA countries [27, 28]. The growing burden of the possible risk factors of body overweight and obesity in women may further affect and exacerbate the burden of DM and its associated complications in the MENA countries.

To develop effective prevention and control interventions, there is a need for understanding the actual burden of pre-DM and T2DM epidemics in vital population groups, such as women of childbearing age (15-49 years), in the MENA region. Thus, individual studies need to be compiled and summarized. According to our previously published protocol (with a slight deviation) [29], here, we present the results of the systematically reviewed published quantitative literature (systematic review "1"), to assess the burden (prevalence) of T2DM and pre-DM in women of childbearing age in the MENA region, from 2000 to 2018.

Investing in women's health paves the way for healthier families and stronger economies. Societies that prioritize 
women's health are likely to have better population health overall and to remain more productive for generations to come [30]. Against this background, our review was aimed at characterizing the epidemiology of T2DM and pre-DM in population groups of women of childbearing age in the MENA through (1) systematically reviewing and synthesizing all available published records of T2DM and pre$\mathrm{DM}$ and (2) estimating the mean T2DM and pre-DM prevalence at national, sub-regional, and regional levels, from January 2000 to July 2018 . The findings of the review fill an evidence gap to inform policy-makers on the epidemiologic burden of T2DM and pre-DM in women of childbearing age.

\section{Methods}

Following our published protocol [29] that is registered with the International Prospective Registry of Systematic Reviews (PROSPERO registration number "CRD42017069231" dated 12/06/2017), we reported here systematic review "1". This review adheres to the Preferred Reporting Items for Systematic Review and Meta-Analysis (PRISMA) 2009 guidelines [31-33]. The PRISMA checklist is provided in the Additional file 1.

\section{Data source and search strategy}

To identify eligible studies on T2DM and pre-DM prevalence measures in MENA countries, we implemented a comprehensive computerized search of six electronic databases (MEDLINE, EMBASE, Web of Science, SCOPUS, Cochrane library, and Academic Search Complete) from January 1, 2000, to July 12, 2018, using variant Medical Subject Headings (MeSH) and free-text (Text) terms. The detailed search strategy is presented in an additional box file (see Additional file 2). We also hand-searched the reference lists of eligible studies for further studies that might have been missed.

We defined the participants, exposure, comparator, outcome(s), and type of study "PECO(T)". The PECO(T) statement provides the framework for the identification and selection of studies for inclusion [34]. As we were looking for prevalence studies, we only considered participants and the outcomes.

\section{Inclusion and exclusion criteria}

Participants: Women of childbearing age were defined according to the World Health Organization (WHO) as women aged between 15 and 49 years (thereafter, women of childbearing age) [35]. Pregnant women were also considered in this review as long as they were tested for T2DM and/or pre-DM according to what was reported in the individual studies.

Outcomes: T2DM and pre-DM. The included studies should have reported quantitative or calculable pre-DM or T2DM prevalence estimate(s) in women of childbearing age regardless of the sample size, pregnancy status, or pre$\mathrm{DM} / \mathrm{T} 2 \mathrm{DM}$ ascertainment methodology, in any of the 20 MENA region countries [36]. We excluded studies of selfreported pre-DM/T2DM not supported with either antiDM medications or a documented diagnosis. We also excluded studies on metabolic syndrome as long as there was no clear information on the proportion of women of childbearing age with pre-DM or T2DM. Studies were also excluded if they pooled women of childbearing age with pre-DM/T2DM with other non-communicable diseases in the same category, or together with males, or for each gender separately but without age stratification. We excluded studies with incalculable pre-DM/T2DM prevalence after attempting to contact the authors at least twice with no response.

Types of studies: We included observational studies if they were cross-sectional, comparative cross-sectional, casecontrol (not comparing T2DM/pre-DM vs. no T2DM/preDM), or cohort study designs. We excluded observational studies of other study designs.

Detailed eligibility criteria are available in the published protocol [29]. The PRISMA flow chart for the selection of studies is shown in Fig. 1.

\section{Identifying eligible studies}

Titles and abstracts of the remaining citations were screened independently by four reviewers (AI, KA, MM, and MQ) for any potential study on pre-DM/T2DM in childbearing age women. Full-texts of the identified potentially eligible studies were thoroughly screened and independently assessed by the four reviewers. The qualities of the extracted studies were independently assessed by two other reviewers (RHA and FA). Discrepancies in data extraction were discussed and resolved.

\section{Data extraction}

Data from fully eligible studies were extracted into a pre-defined data extraction excel file using a pre-defined list of variables [29]. Our outcome of interest was the national/regional weighted pooled prevalence of T2DM and pre-DM in women of childbearing age in the MENA. We extracted the following data on the baseline characteristics of the eligible research reports (author names, year of publication, country, city, and study setting), study methodology (design, time period, sampling strategy, and T2DM/pre-DM ascertainment methodology), and study population (age, pregnancy status, co-morbidity, and number of women with the outcomes of interest).

In research reports which provided stratified T2DM/ pre-DM prevalence estimates, the prevalence of the total sample was replaced with the stratified estimates keeping the rule of having at least 10 tested subjects per strata, otherwise we extracted information on the whole tested sample. We followed a pre-defined sequential order 


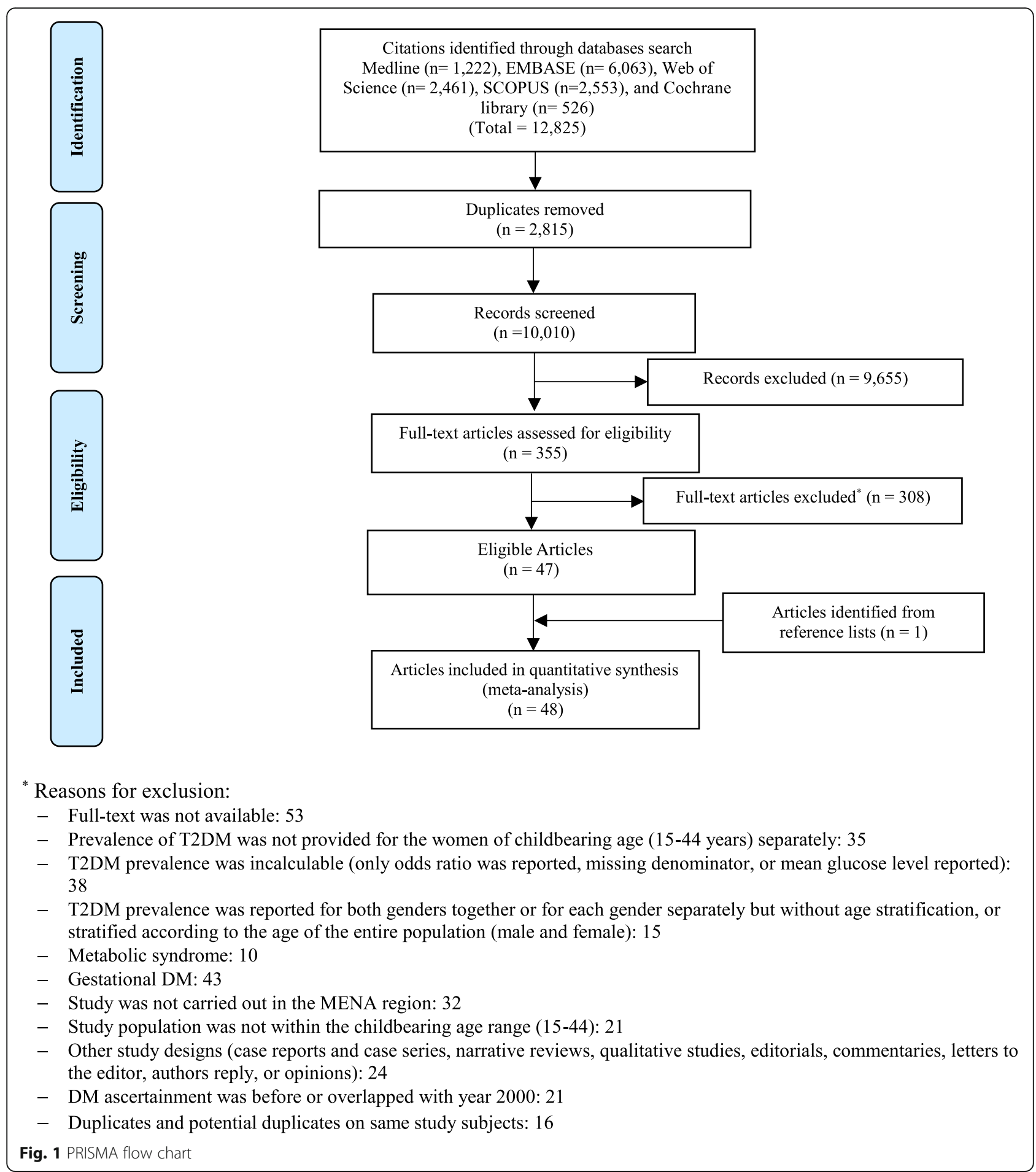

when extracting stratified prevalence estimates. Outcome measures stratified according to body mass index (BMI) were prioritized, followed by age and year. This prioritization scheme was used to identify the strata with more information on the tested women. When the strata were not prioritized, the overall outcome prevalence measured was extracted. For a research report that stratified the prevalence of the outcome of interest at these different levels (i.e., age and BMI), one stratum per research report was considered and included to avoid double counting. If the outcome measure was ascertained by more than one ascertainment guideline, we extracted relevant information based on the most sensitive and reliable ascertainment assay (i.e., prioritizing fasting blood glucose "FBG" 
over self-reported DM status), or the most recent and updated criteria (i.e., prioritizing WHO 2006 over WHO 1999 criteria).

\section{Meta-bias}

We generated a funnel plot to explore the small-study effect on the pooled prevalence estimates. The funnel plot was created by plotting each prevalence measure against its standard error. The asymmetry of the funnel plot was tested using the Egger's test [37] (see Additional files 3 and 4).

\section{Quality appraisal and risk of bias}

We assessed the methodological quality and risk of bias (ROB) of the studies on T2DM or pre-DM prevalence measures using six-quality items adapted from the $\mathrm{Na}$ tional Heart, Lung, and Blood Institute (NIH) tool [38]. Of the 14 items proposed for observational studies on the $\mathrm{NIH}$ tool, eight items were not used as they are relevant only for cohort studies assessing the relationship between an exposure and an outcome [38]. We also assessed the robustness of the implemented sampling methodology and the ascertainment methodology of the measured outcome(s) using three additional quality criteria (sampling methodology, ascertainment methodology, and precision of the estimate). Studies were considered as having "high" precision if at least 100 women tested for T2DM/pre-DM; a reasonable precision, given a pooled prevalence of $7.2 \%$ for T2DM or $7.6 \%$ for pre-DM estimated in this study, was obtained. We computed the overall proportion of research reports with potentially low risk of bias across each of the nine quality criteria. We also computed the proportion (out of nine) of quality items with potentially a low risk of bias for each of the included research reports.

\section{Quantitative synthesis: meta-analysis}

Meta-analyses of the extracted data to estimate the weighted pooled prevalence of T2DM and pre-DM and the corresponding $95 \%$ confidence interval $(\mathrm{CI})$ were executed. The variances of prevalence measures were stabilized by the Freeman-Tukey double arcsine transformation method [39, 40]. The estimated pooled prevalence measures were weighted using the inverse variance method [40], and an overall pooled prevalence estimate was generated using a Dersimonian-Laird random-effects model [41]. Heterogeneity measures were also calculated using the Cochran's $Q$ statistic and the inconsistency index; $I-$ squared $\left(I^{2}\right)$ [42]. In addition to the pooled estimates, the prevalence measures were summarized using ranges and medians. The prediction interval, which estimated the 95\% interval in which the true effect size in a new prevalence study will lie, was also reported [42, 43].

Country-level pooled estimates were generated according to the population group of tested women (general population, pregnant, non-pregnant with history of gestational DM (GDM), and patients with co-morbidity), and the overall country-level pooled prevalence, regardless of the tested population and study period. To assess if the prevalence of T2DM and pre-DM is changing over time, we stratified studies into two time periods: 2000 2009 and 2010-2018. In order not to miss any important data when estimating country-level, sub-regional, and regional prevalence, the period for studies that overlapped these two periods was defined as "overlapping". In studies with an unclear data collection period, we used the median ( $\sim 2$ years) that was obtained from subtracting the year of publication from the year of data collection to estimate the year of data collection in those studies. The "patients with co-morbidity" included women of childbearing age with organ transplant, kidney dialysis, cancer, HIV, chronic obstructive pulmonary disease, polycystic ovarian syndrome (PCOS), or schizophrenia. Categorization of the study period was arbitrary with an aim to estimate the change in T2DM and pre-DM at the country-level and overall, over time.

We also estimated the weighted pooled prevalence, regardless of country, according to the tested women's population group, study period, T2DM/pre-DM ascertainment guidelines (WHO guidelines, American DM Association (ADA) guidelines, International DM Association (IDF) guidelines, or medical records/anti-DM medications/selfreported), and sample size $(<100$ or $\geq 100)$. The overall weighted pooled prevalence of T2DM and pre-DM regardless of the country, tested population, study period, ascertainment guidelines, and sample size was also generated. Providing pooled estimates regardless of the ascertainment guidelines was justified by the fact that the subject women were defined and treated as T2DM or pre-DM patients following each specific ascertainment guidelines.

To provide prevalence estimates at a more sub-regional level, countries in the MENA region were re-grouped into three sub-regions, namely, "Arab Peninsula, Fertile crescent, and North Africa and Iran." The pooled prevalence in these three sub-regions was estimated according to the tested population group, study period, ascertainment guidelines, and sample size, as well as overall for each sub-region.

We also estimated the weighted pooled prevalence of T2DM and pre-DM according to age group. We categorized women of childbearing age into three age groups (15-29 years, 30-49 years) and not specified/overlapping. The "not specified/overlapping" category covers women who did fell in the other two age groups. For example, women with an age range of 25-34 years or 18-40 years. The age group weighted pooled prevalence produced regardless of the country, sub-region, and tested population as well as study period.

All meta-analyses were performed using the metaprop package [33] in Stata/SE v15 [44]. 


\section{Sources of heterogeneity: meta-regression}

Random-effects univariate and multivariable metaregression models were implemented to identify sources of between-study heterogeneity and to quantify their contribution to variability in the T2DM and pre-DM prevalence. In univariate meta-regression models, analysis was performed by country, tested population, study period, ascertainment guidelines, and sample size. All variables with a $p<0.1$, in the univariate models, were included in the multivariable model. In the final multivariable model, a $p$ value $\leq 0.05$ was considered statistically significant, contributing to heterogeneity in prevalence estimates.

All meta-regression analyses were performed using the metareg package in Stata/SE v15 [44].

\section{Results}

\section{Search and eligible research reports}

Of the 12,825 citations retrieved from the six databases, 48 research reports were found eligible (Fig. 1); 46 reported T2DM prevalence [45-90] while 24 reported preDM prevalence $[48,49,51-57,60,62,63,66,67,70,73$, 75, 81, 85, 88-90].

\section{Scope of reviewed T2DM reports}

The 46 research reports on T2DM prevalence yielded 102 T2DM prevalence studies. The 46 reports were from 14 countries (Algeria, Egypt, Iran, Iraq, Jordan, Kuwait, Lebanon, Morocco, Oman, Qatar, Saudi Arabia, Tunisia, the United Arab Emirates [UAE], and Yemen); ranging by year between 2000 in Saudi Arabia [79] and 2018 in UAE [81]. Sixteen (34.9\%) research reports were reported in Saudi Arabia [64-79], followed by $19.6 \%$ in the UAE [81-89], and $15.2 \%$ in Iran [47-53]. Over one third (37.3\%) of the yielded 102 T2DM prevalence studies were in Saudi Arabia. Of the 102 T2DM prevalence studies, $79.4 \%$ were in women sampled from general populations and $11.8 \%$ in pregnant women. Over two thirds $(69.6 \%)$ of the T2DM prevalence studies were in or before 2009 and $82.4 \%$ tested $\geq 100$ women (Table 1).

\section{Pooled T2DM prevalence}

In the 14 countries, the weighted T2DM prevalence in women of childbearing age estimated at 7.5\% (95\% CI, 6.1-9.0\%, $I^{2}, 98.2 \%$ ) (Table 2, Fig. 2). The weighted T2DM prevalence was not significantly different $(p=0.4)$ in studies reported between 2000 and 2009 (7.9\%, 95\% CI, 6.29.7\%, $\left.I^{2}, 97.9 \%\right)$ and studies reported between 2010 and 2018 (5.8\%, 95\% CI, 3.4-8.7\%, I², 95.4\%) (Table 2). The weighted T2DM prevalence was higher in women with an age range of $15-19$ years $\left(10.9 \%, 95 \% \mathrm{CI}, 8.8-13.3 \%, I^{2}\right.$, $97.9 \%)$ than women with an age range of 30-49 years (2.5\%, 95\% CI, 1.8-3.2\%, $I^{2}, 83.6 \%$ ) (see Additional file 5).

The highest two weighted T2DM estimates were observed in infertile women of childbearing age in Egypt
(28.2\%, 95\% CI, 17.4-40.3\%) and in non-pregnant women with a history of GDM in Iran $(24.7 \%$, 95\% CI, $18.5-$ $31.5 \%$ ) (Table 2). In general populations, the weighted T2DM prevalence ranged between 1.3\% (95\% CI, 0.04.7\%) in 2001-2002 in Morocco [60] and 16.4\% (95\% CI, $\left.6.5-29.8 \%, I^{2}, 96.5 \%\right)$ in Iraq in 2007 [55] and in 20112012 [54]. In Saudi Arabia, in women of childbearing age sampled from general populations, the pooled T2DM prevalence estimated at $8.0 \%\left(95 \% \mathrm{CI}, 5.3-11.3 \%, I^{2}\right.$, 96.5\%) (Table 1). In Saudi Arabia, the weighted T2DM prevalence in women of childbearing age, regardless of source of population and timeline, estimated at $7.2 \%$ (95\% CI, 4.6-10.2\%, $I^{2}, 98.6 \%$ ) (Table 2). In Oman, the weighted T2DM prevalence in women of childbearing age sampled from general populations estimated at 8.0\% (95\% CI, 2.9$\left.15.4 \%, I^{2}, 95.9 \%\right)$ in 2000 . In Qatar, the weighted T2DM was prevalence in women of childbearing age sampled from general populations $10.7 \%$ (95\% CI, 2.2-24.4\%, $I^{2}$, 93.7\%) between 2007 and 2008. In the UAE, in women of childbearing age sampled from general populations, the pooled T2DM prevalence estimated at 8.0\% (95\% CI, 4.8$\left.11.9 \%, I^{2}, 98.9 \%\right)$ that declined from $9.4 \%$ (95\% CI, 5.6$14.1 \%, I^{2}, 95.1 \%$ ) between 2000 and 2009 to $6.0 \%$ (95\% CI, $3.3-6.5 \%, I^{2}, 90.5 \%$ ) between 2010 and 2018 (Table 2).

\section{Sub-regional pooled T2DM prevalence}

The pooled T2DM prevalence measures estimated at 6.5\% (95\% CI, 4.3-9.1\%, $\left.I^{2}, 96.0 \%\right)$ in North African countries including Iran, $10.7 \%$ (95\% CI 5.2-17.7\%, $I^{2}$, 90.7\%) in the Fertile Crescent countries, and 7.6\% (95\% CI, 5.9-9.5\%, $\left.I^{2}, 98.5 \%\right)$ in the Arabian Peninsula countries (see Additional file 6).

Additional file 7 shows figures presenting the subregional-weighted prevalence of T2DM (Fig. 1) in women of childbearing age from 2000 to 2009 and from 2010 to 2018. Additional file 8 shows figures presenting timeline view of the weighted prevalence of T2DM (Fig. 1) by publication year.

\section{Meta-bias in T2DM prevalence}

The asymmetry in the funnel plot examining the smallstudy effects on the pooled T2DM prevalence among women of childbearing age indicates evidence for the presence of a small-study effect (Egger's test $p<0.0001$ ). The funnel plot is presented in an additional figure file (see Additional file 3).

\section{Predictors of heterogeneity in T2DM prevalence}

In the univariate meta-regression models, all variables except study period, T2DM ascertainment criteria, and sample size were associated with T2DM prevalence at $p$ value $<0.1$. In the adjusted meta-regression model, none of the included variables was significantly associated with T2DM prevalence at $p$ value $<0.05$. In two studies 


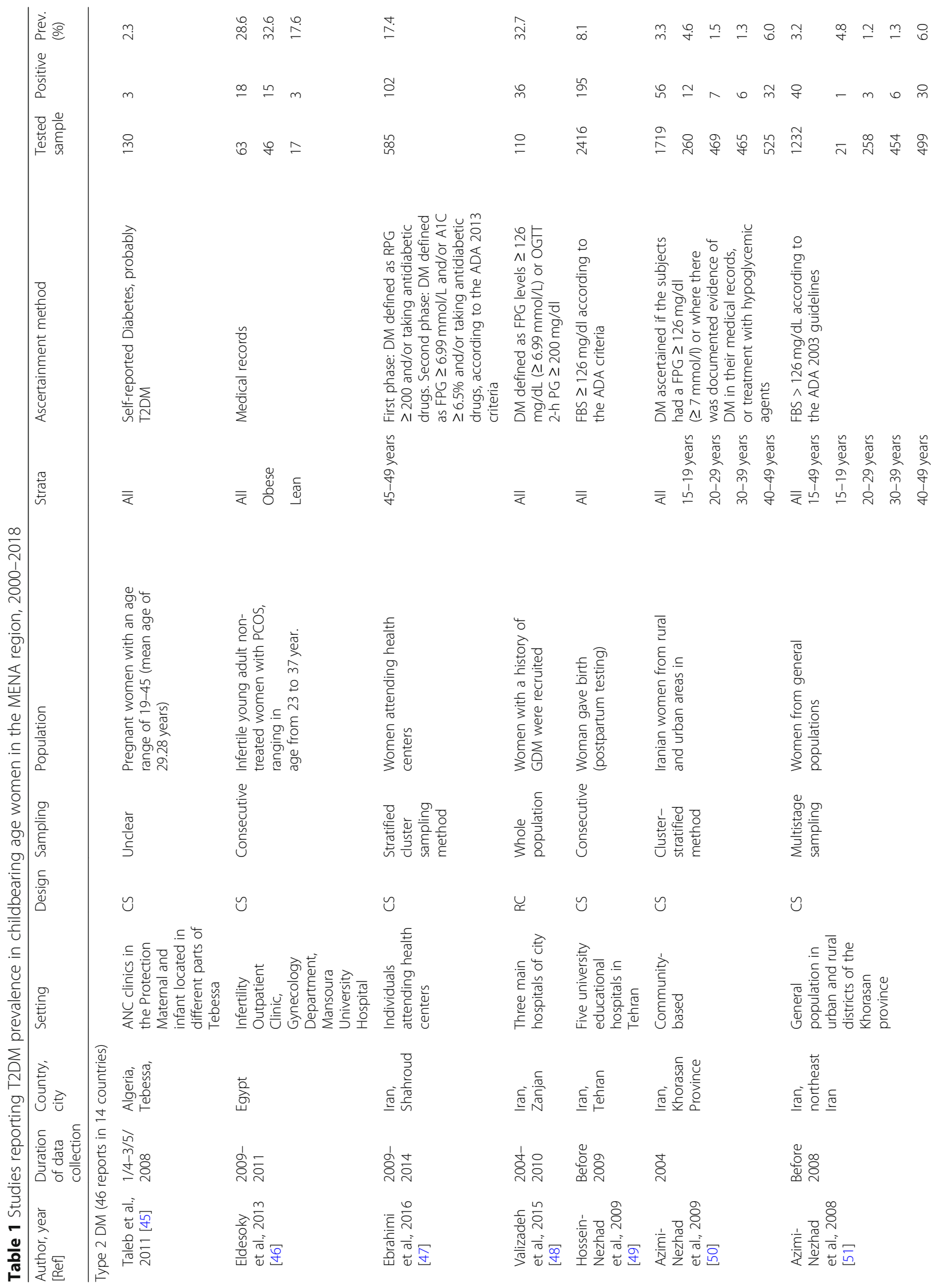




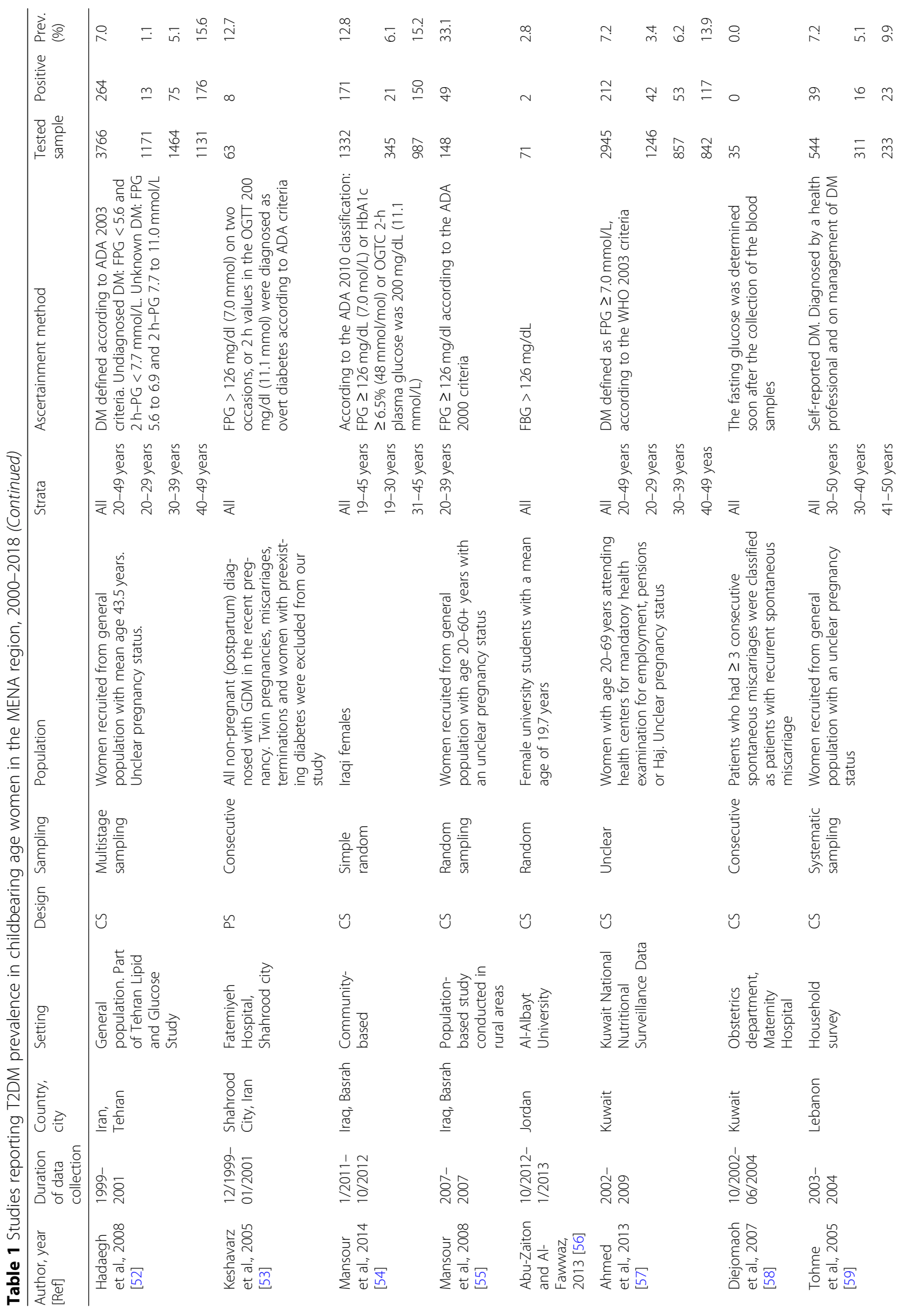


Al-Rifai et al. Systematic Reviews

(2019) 8:268

Page 9 of 32

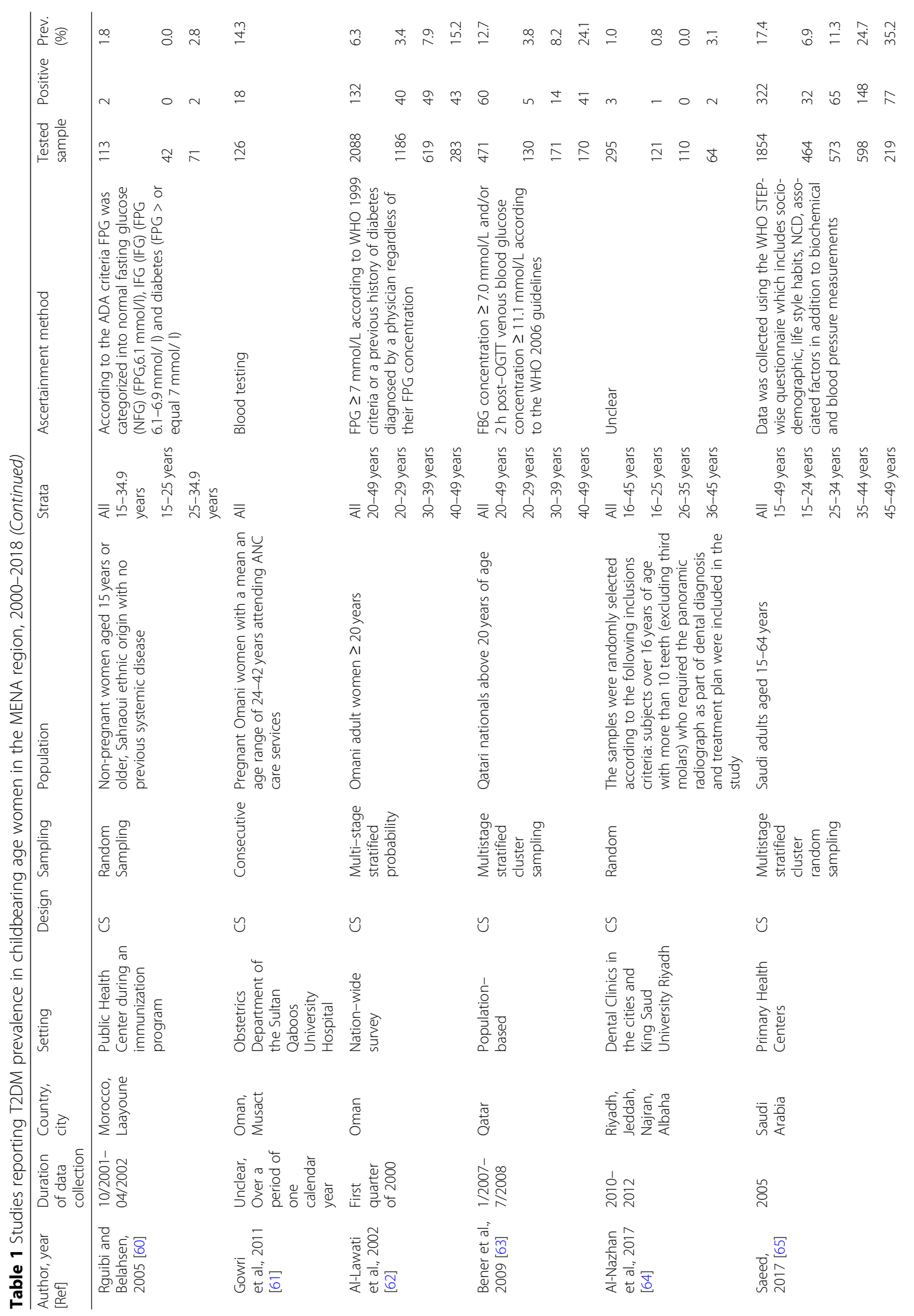




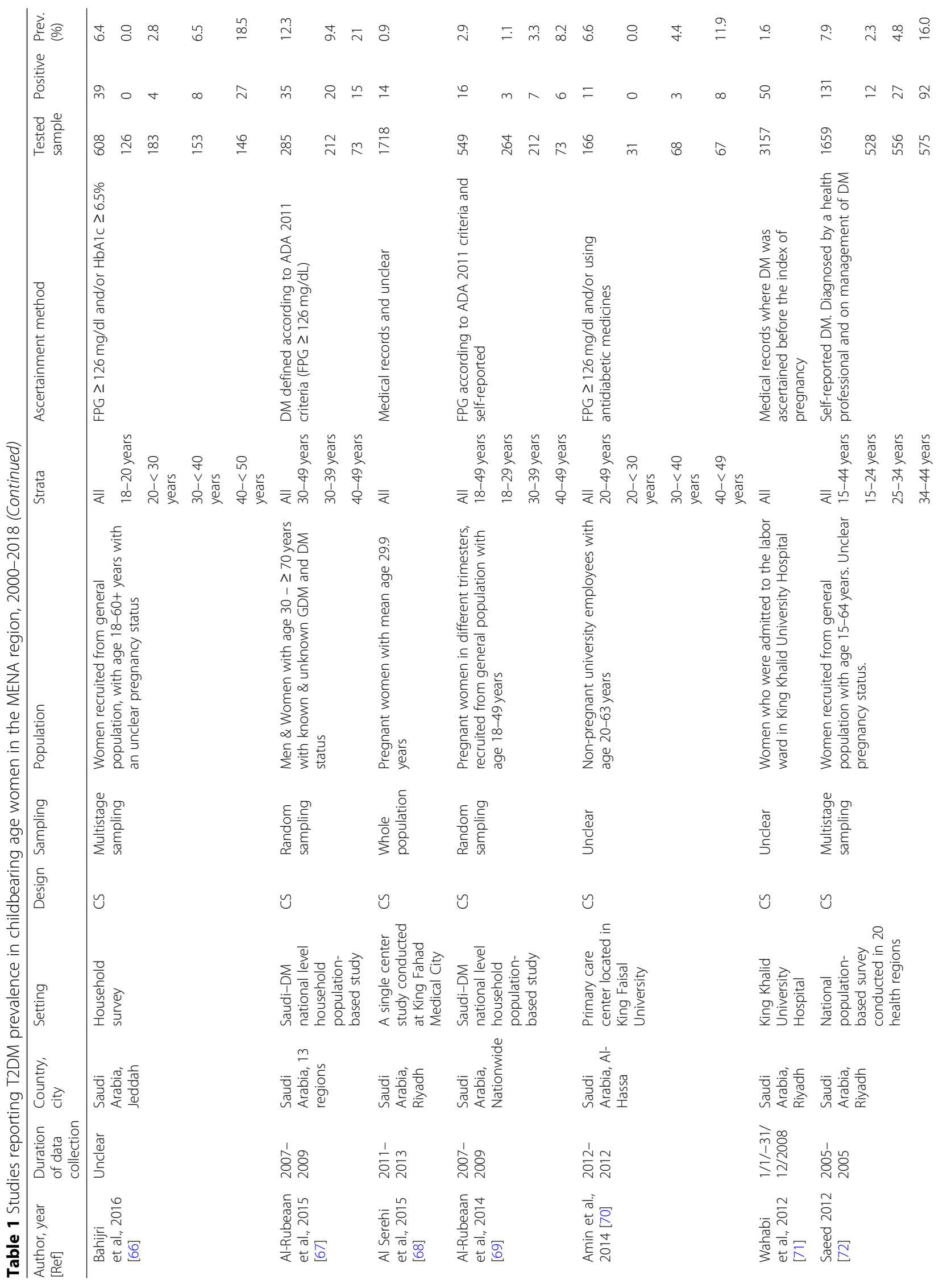




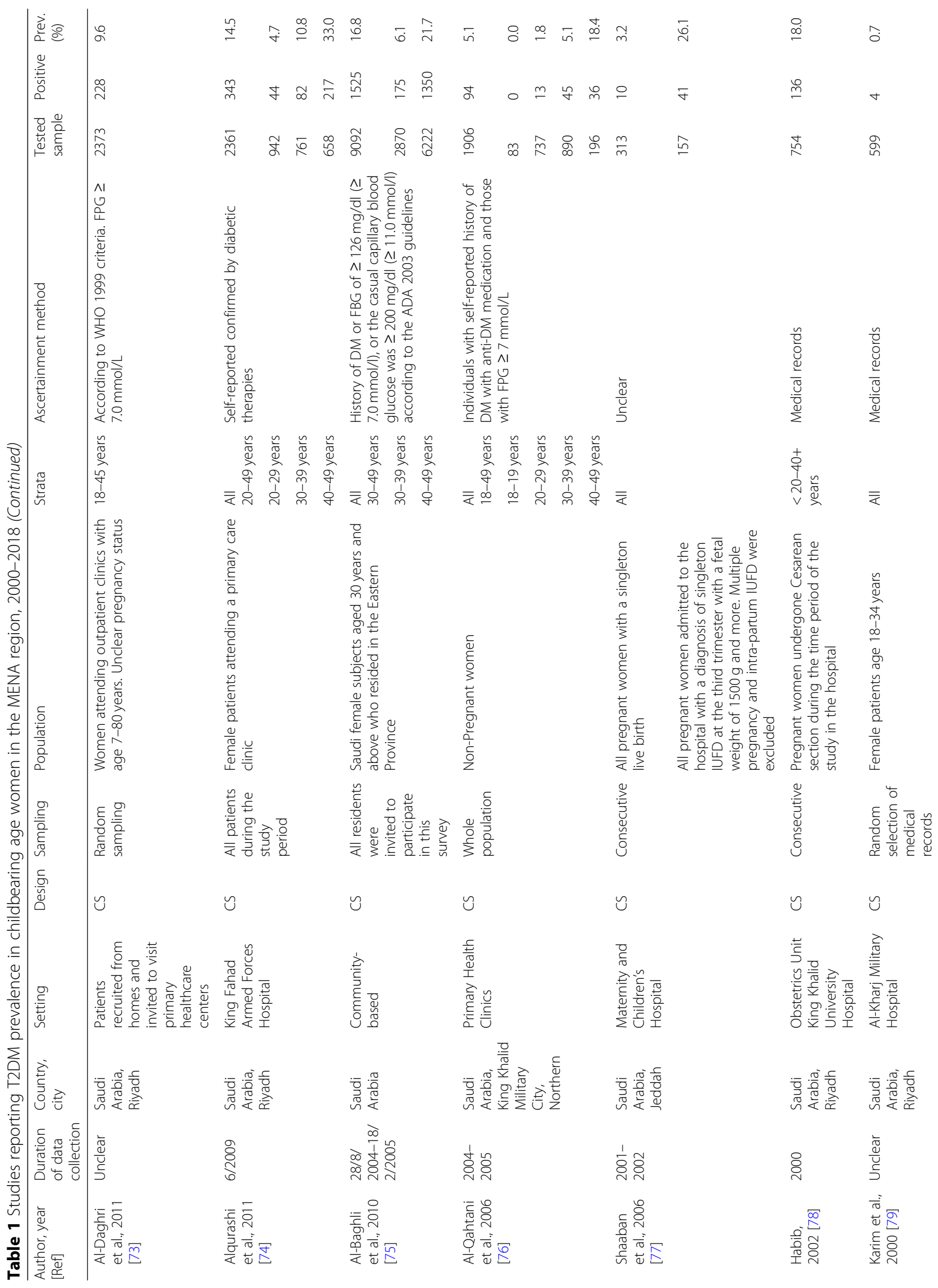




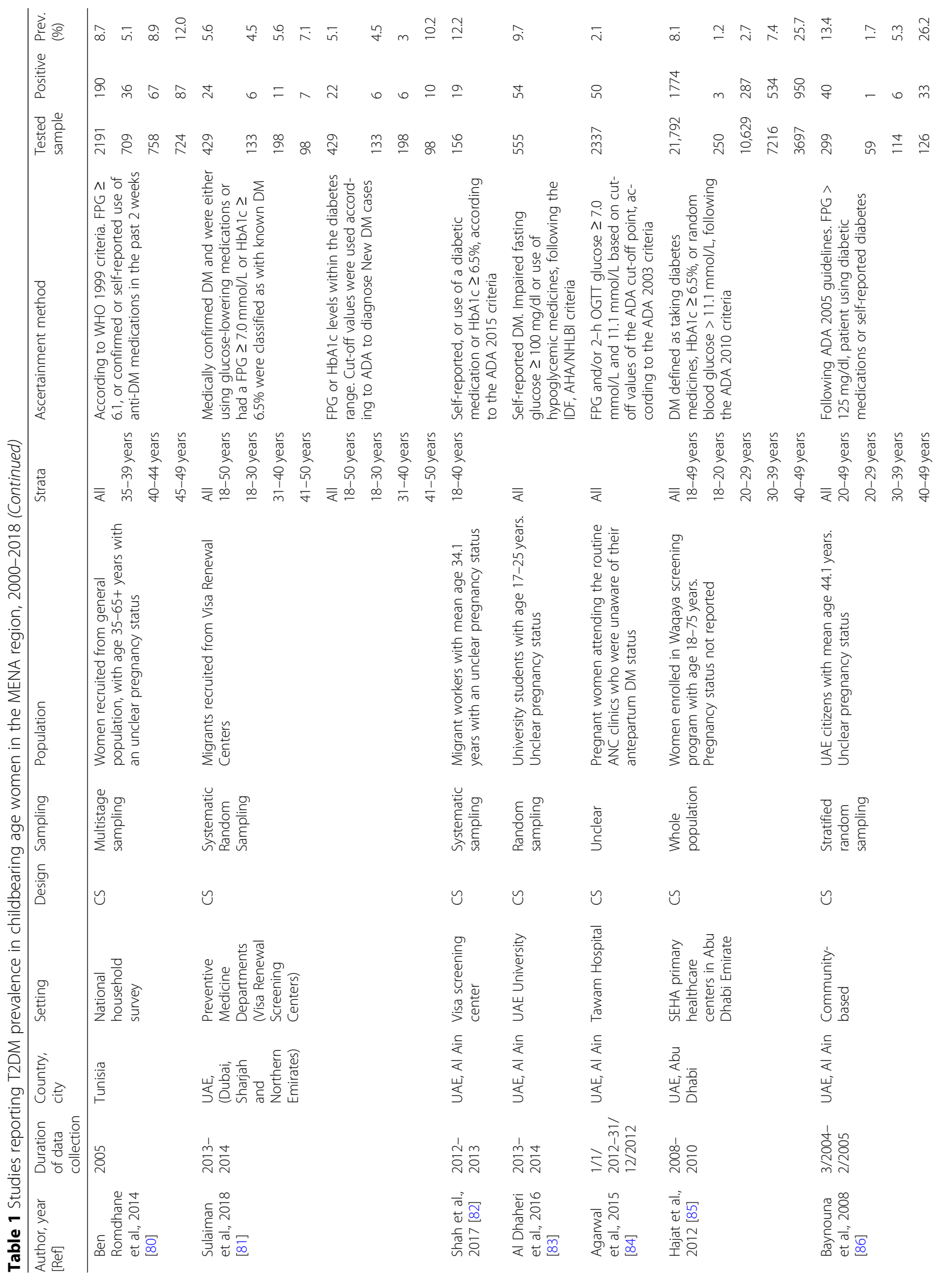




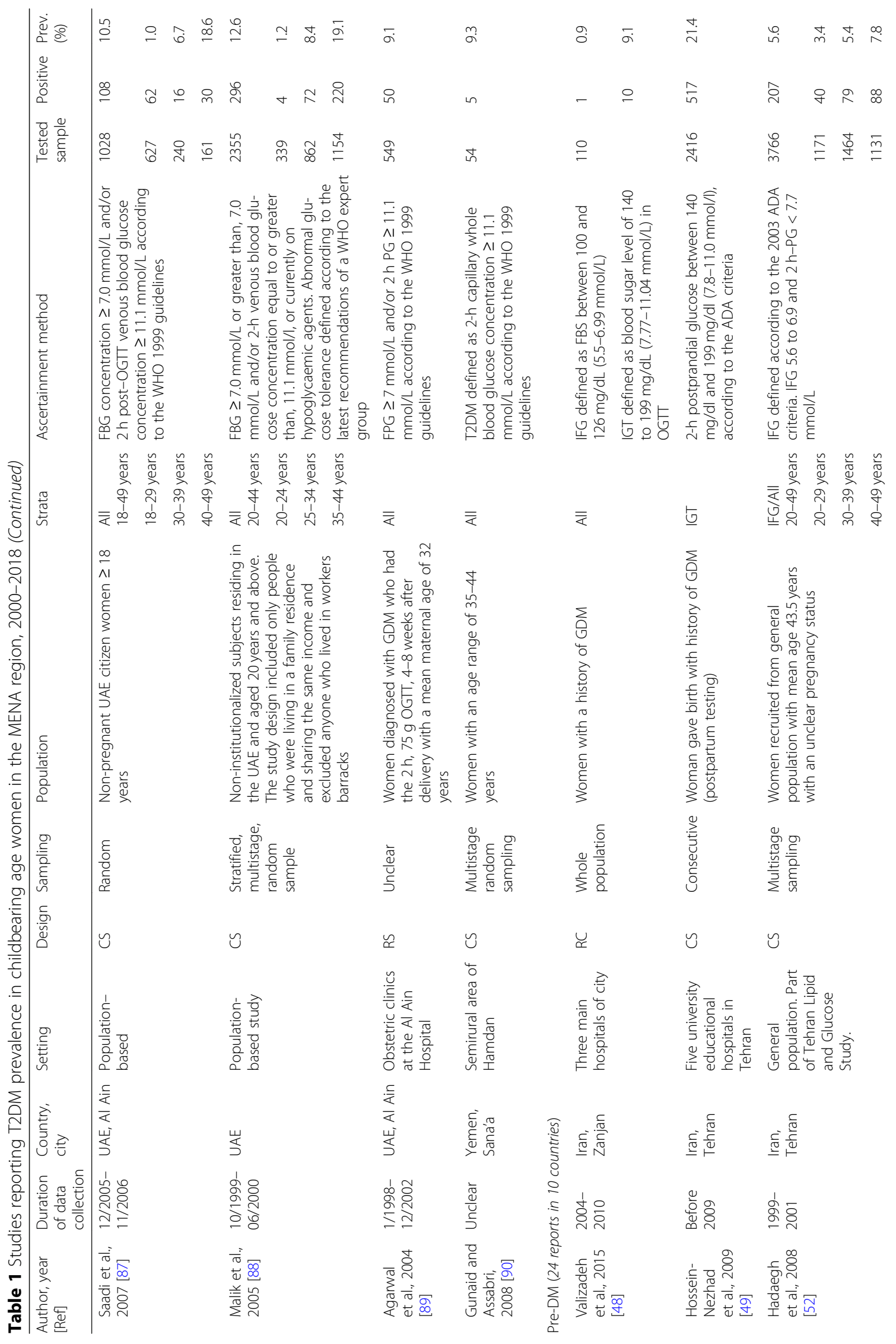




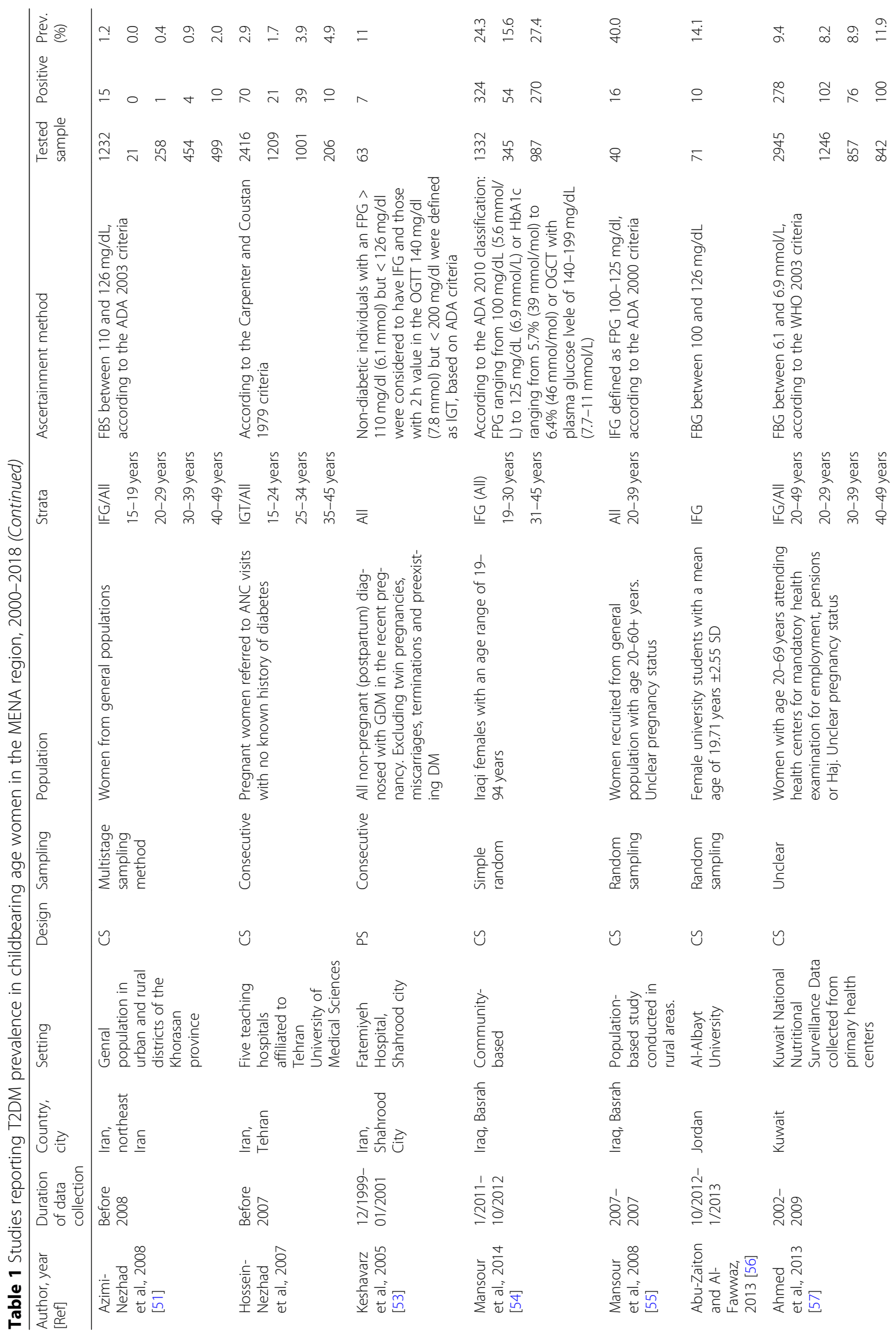


Al-Rifai et al. Systematic Reviews $\quad$ (2019) 8:268

Page 15 of 32

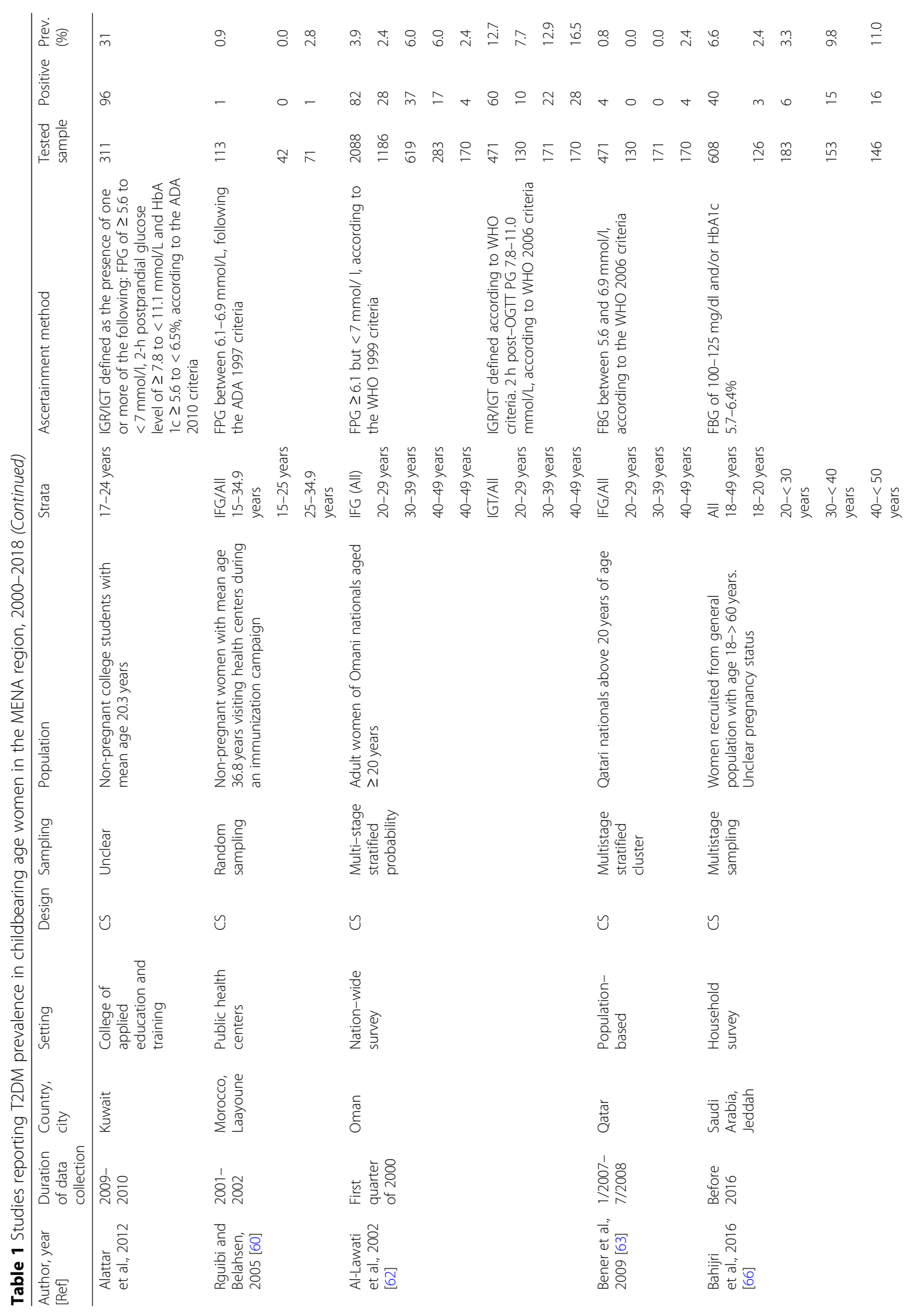




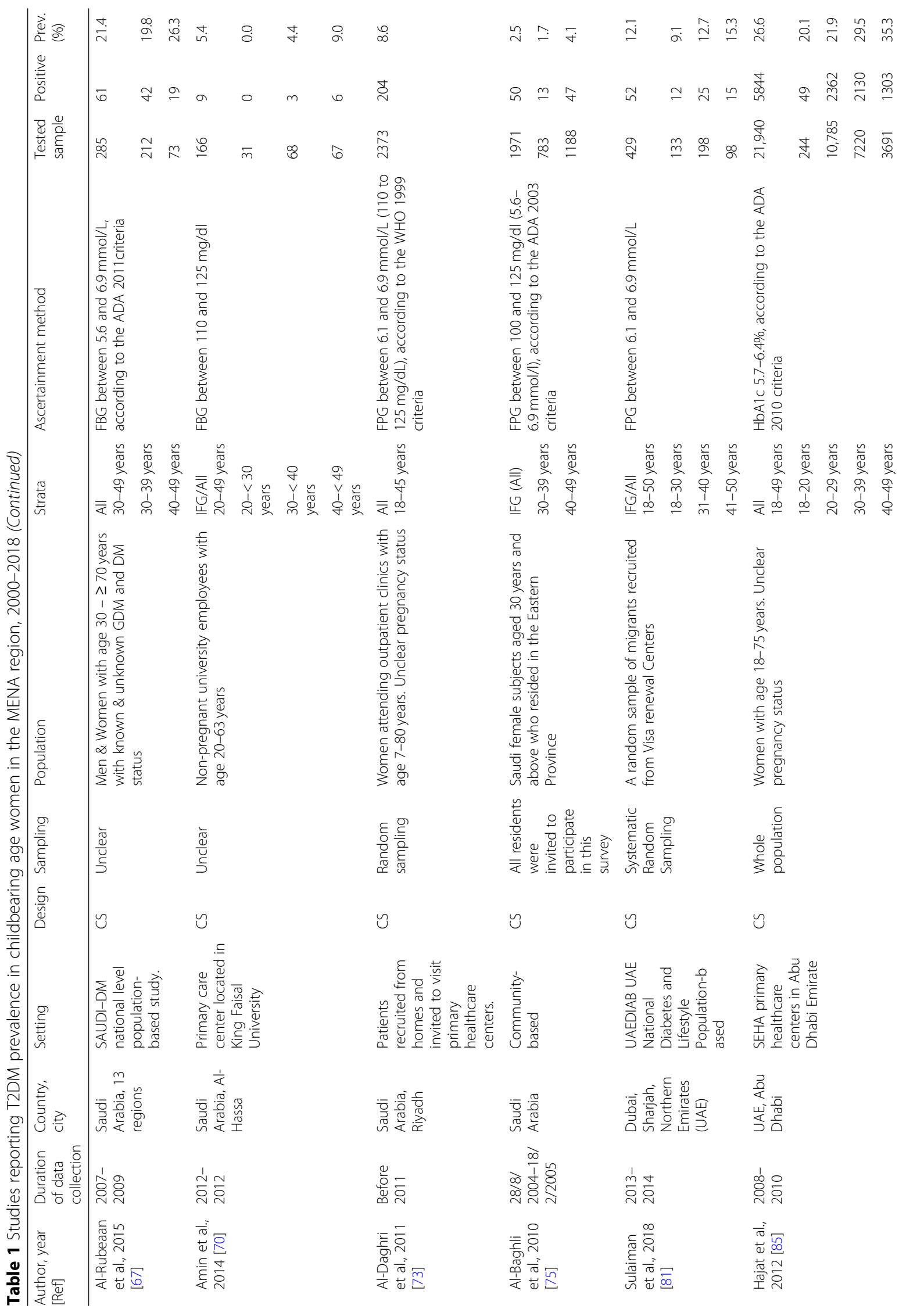


Al-Rifai et al. Systematic Reviews

(2019) 8:268

Page 17 of 32

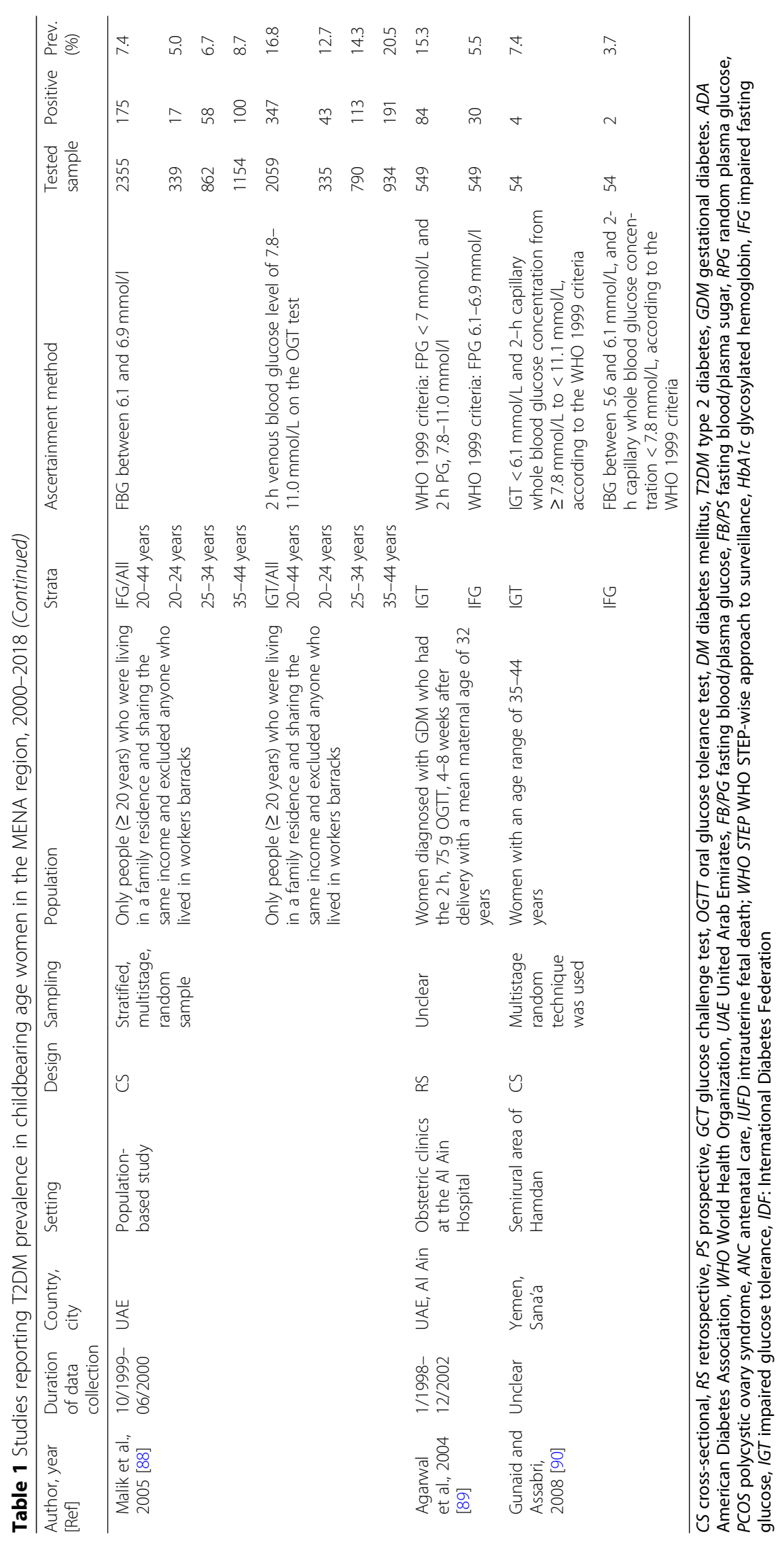




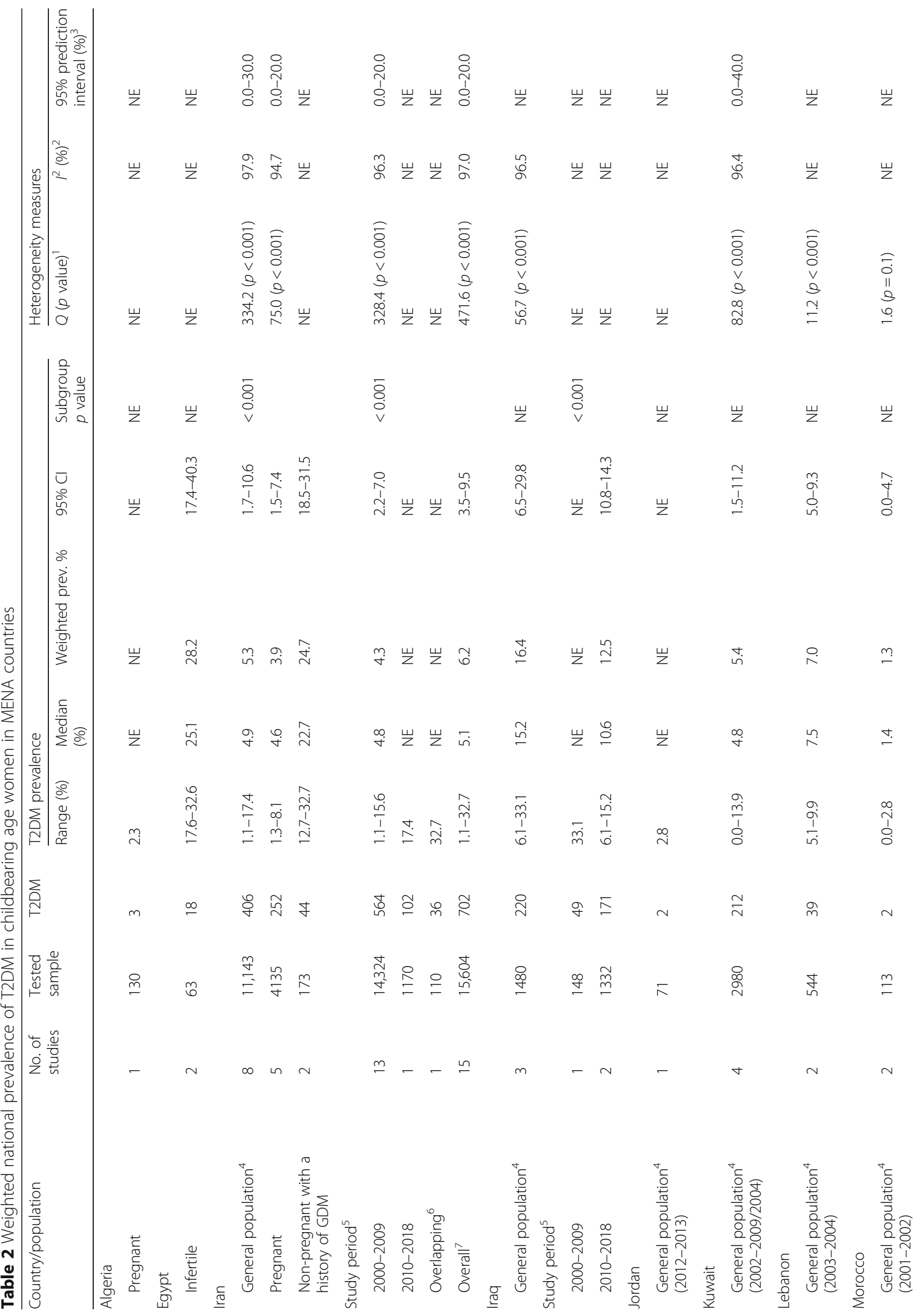


Al-Rifai et al. Systematic Reviews

(2019) 8:268

Page 19 of 32

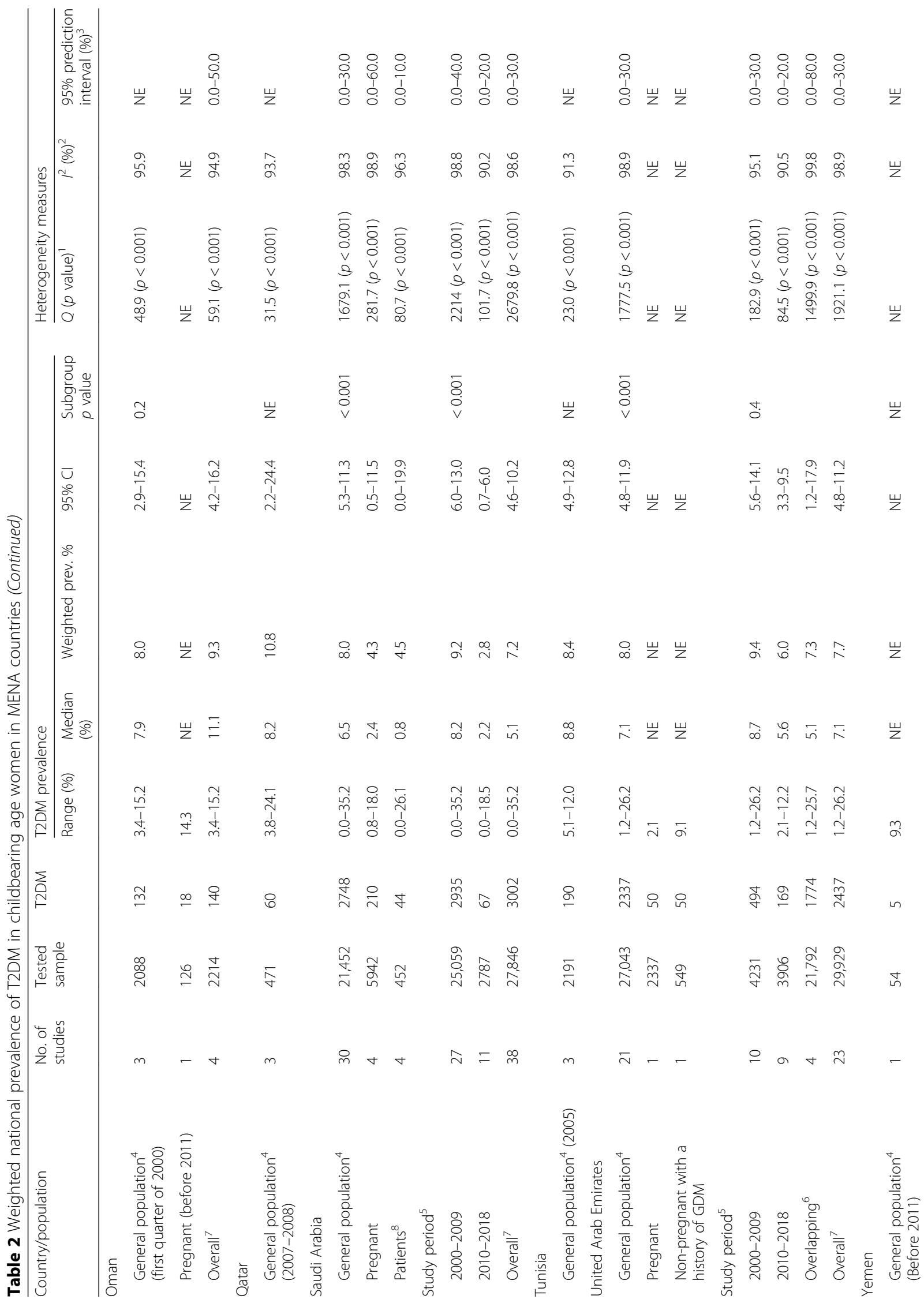




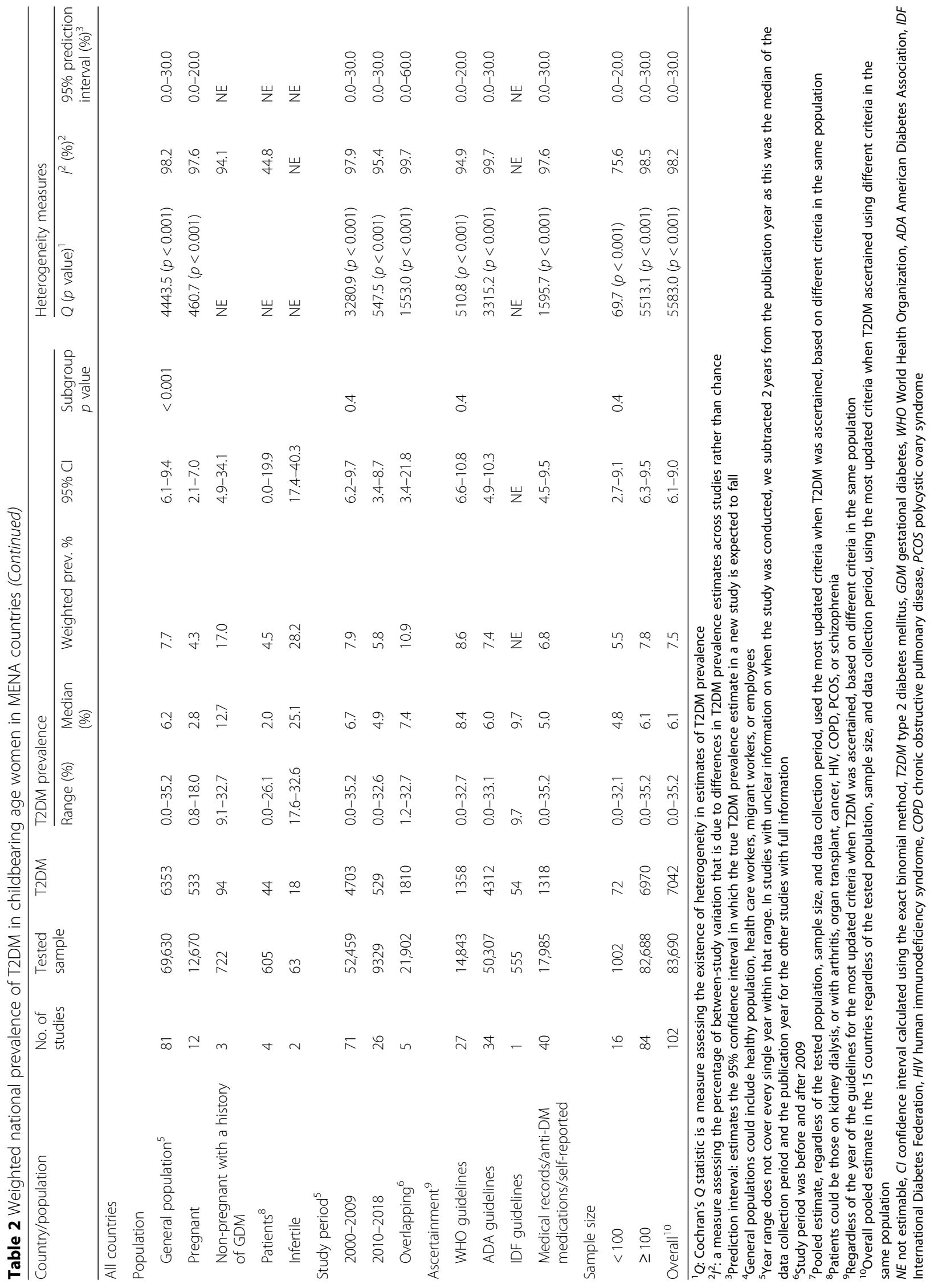




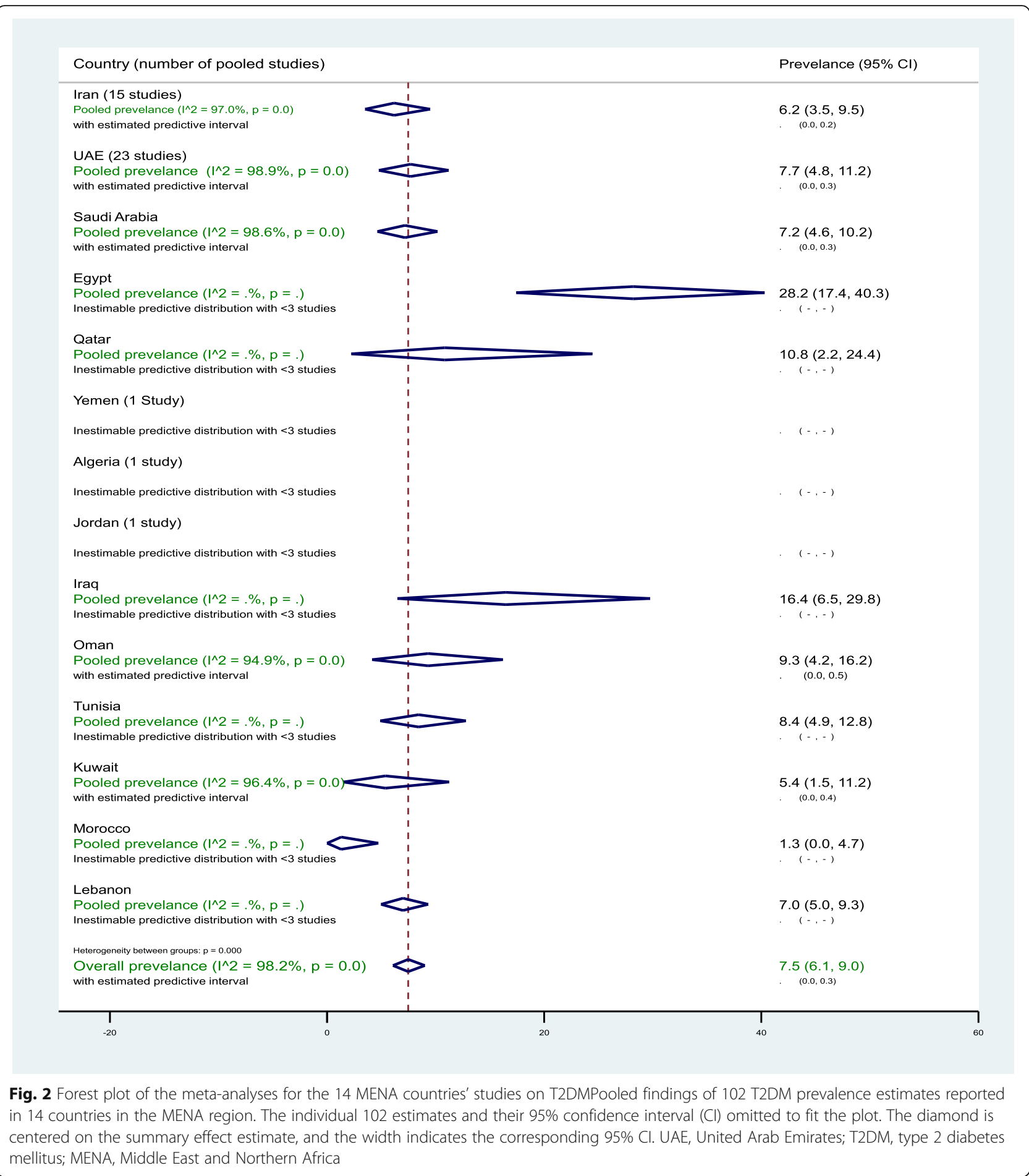

in infertile women of childbearing age in Egypt, the T2DM prevalence was higher (adjusted odds ratio (aOR), 5.26, 95\% CI, 0.87-32.1) compared to women of childbearing age in Saudi Arabia. Overall, compared to women of childbearing age sampled from general populations, T2DM prevalence in non-pregnant women of childbearing age with a history of GDM was $234 \%$ higher (aOR, 3.34\%, 95\% CI, 0.90-12.41) (see Additional file 9).

\section{Scope of reviewed pre-DM reports}

The 24 research reports on pre-DM prevalence yielded 52 pre-DM prevalence studies and were from 10 
countries (Iran, Iraq, Jordan, Kuwait, Morocco, Oman, Qatar, Saudi Arabia, UAE, and Yemen); ranging by year between 2002 in Oman [62] and 2018 in Saudi Arabia [81]. Thirteen (25.0\%), $11(21.2 \%)$, and $11(21.2 \%)$ of the pre-DM prevalence studies were from Iran, Saudi Arabia, and UAE, respectively. Approximately $87.0 \%$ of the pre-DM prevalence studies tested women of childbearing age sampled from general populations. The pre-DM prevalence estimates ranged from $0.0 \%$ in various age groups in multiple countries $[51,60,70]$ to $40.0 \%$ in Iraq in women aged 20-39 years, recruited from the general population [55] (Table 1).

\section{Pooled pre-DM prevalence}

In the 10 countries, the weighted pre-DM prevalence in women of childbearing age was estimated at 7.6\% (95\% CI, 5.2-10.4\%, $I^{2}$, 99.0\%) (Table 3, Fig. 3). The weighted pre-DM prevalence in studies reported between 2000 and $2009\left(4.8 \%, 95 \%\right.$ CI $\left.4.0-7.8 \%, I^{2}, 97.1 \%\right)$ was significantly lower $(p<0.001)$ than the weighted prevalence estimated in studies reported between 2010 and 2018 (9.3\%, 95\%, 4.7-15.2\%, $I^{2}, 93.9 \%$ ) (Table 3). Weighted pre-DM prevalence was 1.70 times higher in women with an age range of $15-19$ years $(9.0 \%, 95 \% \mathrm{CI}, 4.9-$ $\left.14.1 \%, I^{2}, 99.2 \%\right)$ than women with an age range of $30-$ 49 years $\left(5.3 \%, 95 \%\right.$ CI, $1.8-10.3 \%, I^{2}, 99.0 \%$ ) (see Additional file 5).

In general populations, the highest three weighted preDM prevalence estimates were observed in women of childbearing age in Iraq $\left(25.5 \%, 95 \% \mathrm{CI}, 15.4-37.1 \%, I^{2}\right.$, 92.2\%), followed by UAE $\left(15.5 \%, 95 \%\right.$ CI, $10.5-21.2 \%, I^{2}$, 99.0\%), and Kuwait (13.8\%, 95\% CI, $7.7-21.4 \%, I^{2}$, 96.8\%) (Table 3). In 13 studies in Iran (7 from the general population), the prevalence of pre-DM ranged from 0.0 to $21.4 \%$ with an overall weighted prevalence of $3.8 \%$ (95\% CI, $1.2-7.6 \%, I^{2}, 98.3 \%$ ). The 11 pre-DM studies in Saudi Arabia were in women of childbearing age sampled from the general population, with an overall weighted preDM prevalence of $6.6 \%$ (95\% CI, 3.7-10.3\%, $I^{2}, 93.5 \%$ ) (2000-2009: 9.4\% vs. 2010-2018: 4.4\%). Regardless of the tested population in UAE, the weighted pre-DM prevalence was $6.6 \%\left(95 \% \mathrm{CI}, 5.1-8.3 \%, I^{2}, 65.6 \%\right)$ in studies reported between 2000 and 2009, and 12.0\% (95\% CI, 8.9$15.5 \%$ ) in studies reported between 2010 and 2018 with an overall pre-DM prevalence of $14.4 \%$ (95\% CI, 9.5-20.0\%, $I^{2}$, 99.1\%) (Table 3).

\section{Sub-regional pooled pre-DM prevalence}

The pooled pre-DM prevalence estimated at 3.3\% (95\% CI, 1.0-6.7\%, $\left.I^{2}, 98.1 \%\right)$ in North African countries including Iran, $22.7 \%$ (95\% CI, 14.2-32.4\%, $I^{2}, 90.0 \%$ ) in the Fertile crescent countries, and $8.6 \%\left(95 \% \mathrm{CI}, 5.5-12.1 \%, I^{2}\right.$, 99.1\%) in the Arabian Peninsula countries (see Additional files 10). Additional file 7 shows figures presenting the sub-regional weighted prevalence of pre-DM (Fig. 2) in women of childbearing age from 2000 to 2009 and from 2010 to 2018. Additional file 8 shows figures presenting timeline view of the weighted prevalence of pre-DM (Fig. 2 ) by publication year.

\section{Meta-bias in pre-DM prevalence measures}

The asymmetry in the funnel plot examining the smallstudy effects on the pooled pre-DM prevalence among women of childbearing age indicates evidence for the presence of a small-study effect (Egger's test $p<0.0001$ ). The funnel plot is presented in an additional figure file (Additional file 4).

\section{Predictors of heterogeneity in pre-DM prevalence}

Country, study period, and pre-DM ascertainment criteria were associated with a difference in the pre-DM prevalence in the univariate meta-regression models at $p$ value $<0.1$. In the univariate meta-regression models, pre-DM prevalence in women of childbearing age in Iraq was $424 \%$ higher compared to such women in Saudi Arabia (OR, 5.24, 95\% CI, 1.45-18.94\%). This significant association turned insignificant in the multivariable model (aOR, 2.20, 95\% CI, 0.52-10.82\%). In the multivariable model, compared to Saudi Arabia, pre-DM prevalence in women of childbearing age was $70 \%$ lower in Iran $(\mathrm{aOR}$, $0.30,95 \% \mathrm{CI}, 0.11-0.79 \%)$ and $88 \%$ lower in Morocco (aOR, 0.12, 95\% CI, 0.01-0.91\%) (see Additional file 11).

\section{Quality assessment of the T2DM/pre-DM research reports}

Findings of our summarized and research report-specific quality assessments for relevant DM prevalence studies can be found in Additional file 12. Briefly, all the 48 research reports clearly stated their research questions or objectives, clearly specified and defined their study populations, and selected or recruited the study subjects from the same or similar populations. There was a clear gap in the reporting or justifying of the sample size calculation in $79.2 \%$ of the research reports. The majority (87.5\%) of the research reports tested $\geq 100$ women of childbearing age, and they were classified as having high precision.

Overall, the 48 research reports were of reasonable quality with potentially low $\mathrm{ROB}$ in an average of 7.2 items (range, $6-9$ ). Four (8.3\%) of the 48 reports had potentially low $\mathrm{ROB}$ in all the measured nine quality items [66, 82, 83, 86] (see Additional file 12).

\section{Discussion}

We provided, to our knowledge, the first regional study that comprehensively reviewed and estimated the regional, sub-regional, and country-level burden of T2DM and pre$\mathrm{DM}$ in various populations of women of childbearing age in the MENA. Based on the available data from 14 and 10 studies in MENA countries, the present findings document 


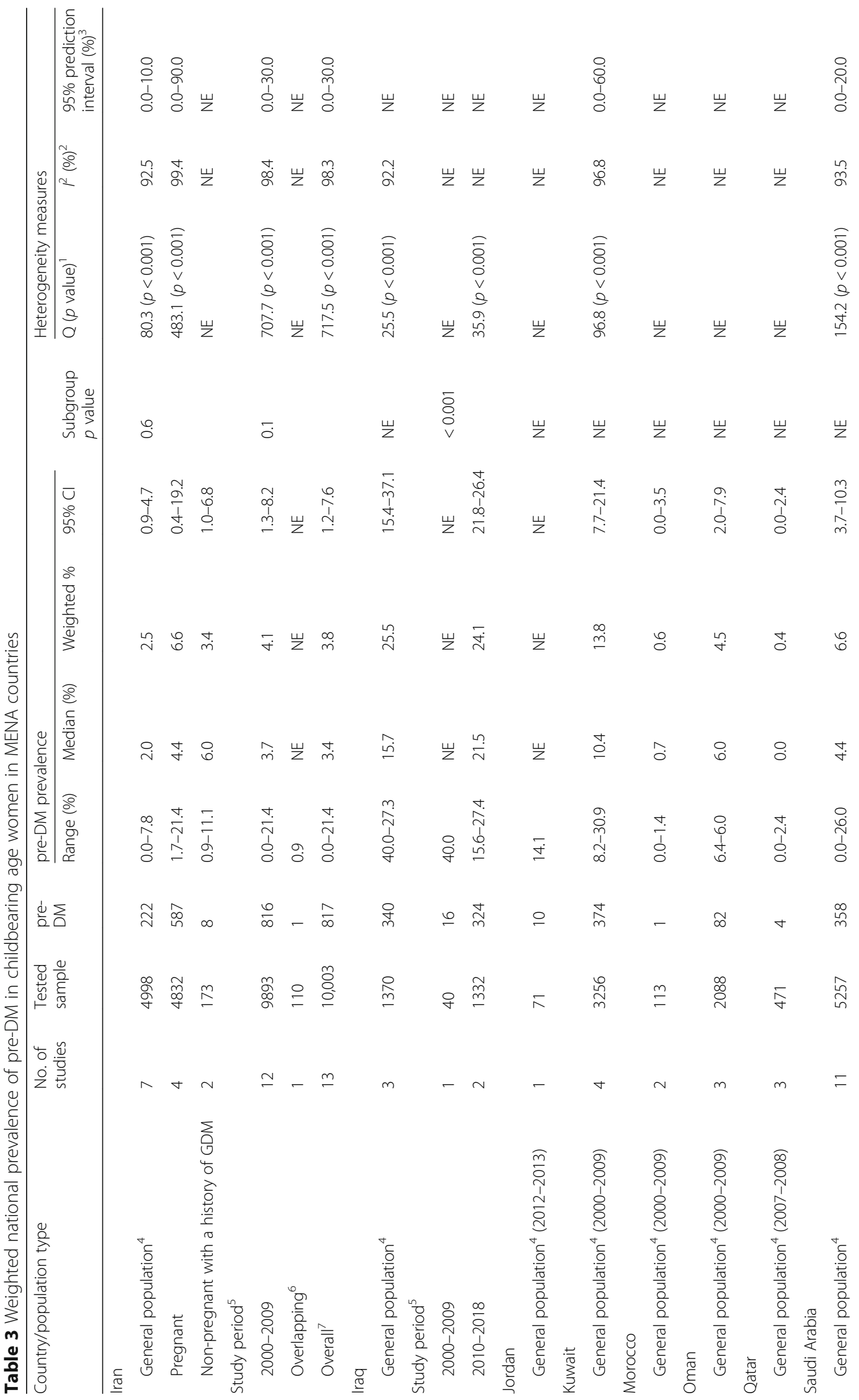




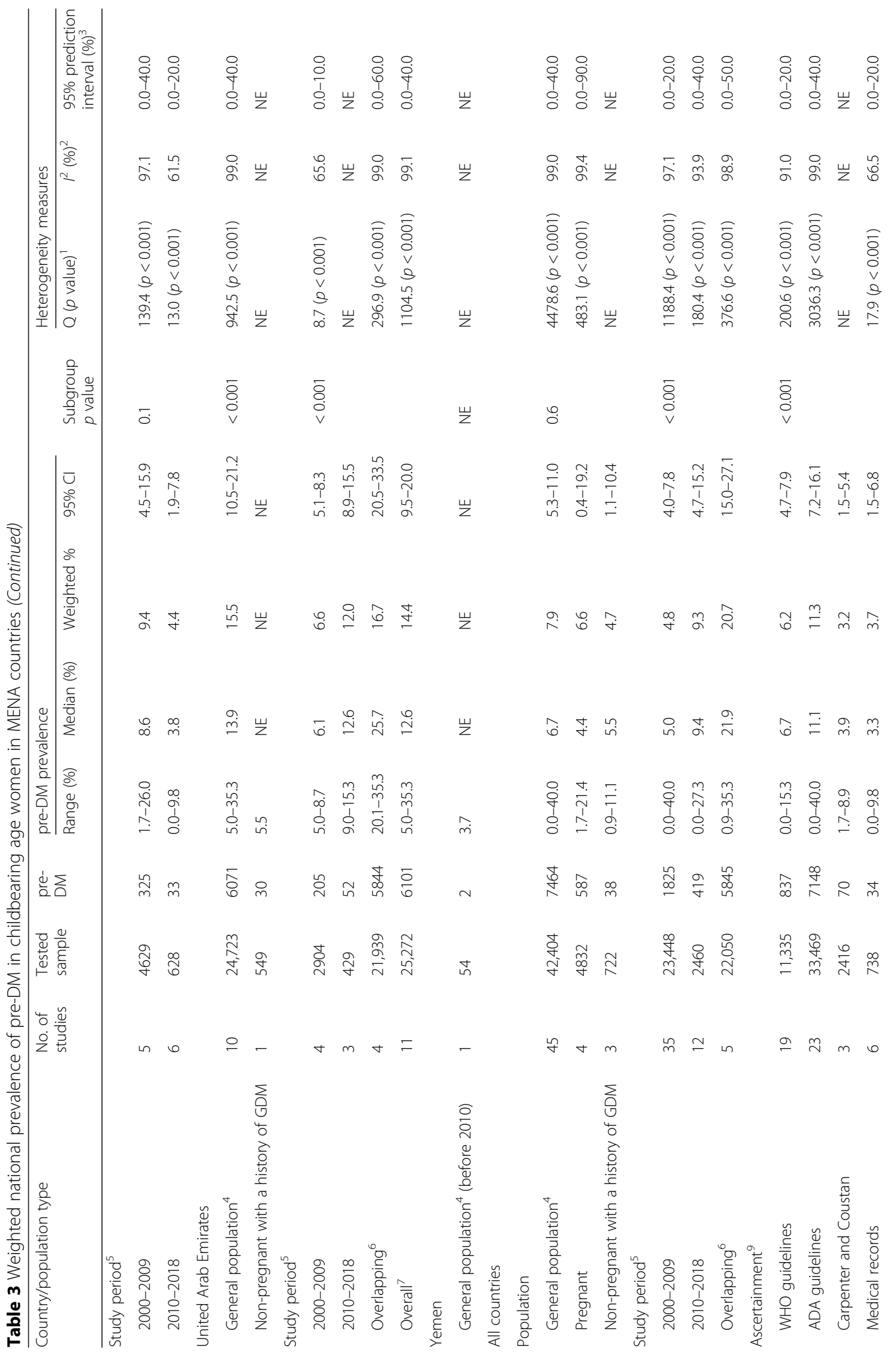




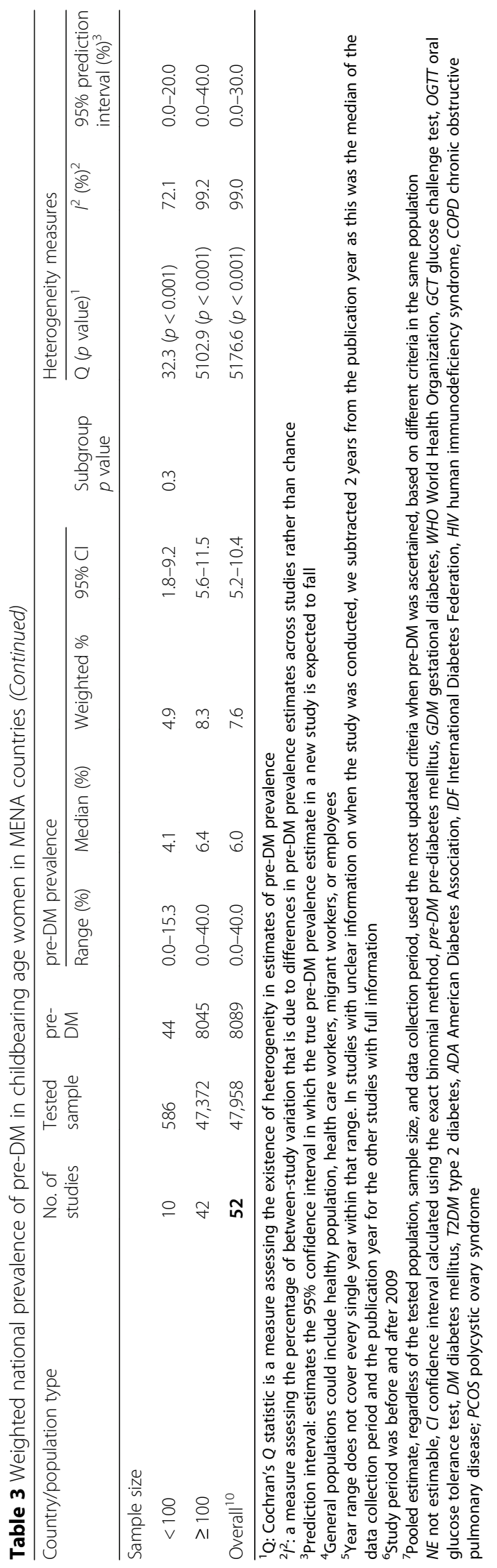




\section{Iran}

Pooled prevelance $\left(\left.\right|^{\wedge} 2=98.3 \%, p=0.0\right)$

with estimated predictive interval

\section{UAE}

Pooled prevelance $\left(\left.\right|^{\wedge} 2=99.1 \%, p=0.0\right)$

with estimated predictive interval

Saudi Arabia

Pooled prevelance $\left(I^{\wedge} 2=93.5 \%, p=0.0\right)$

with estimated predictive interval

Qatar

Pooled prevelance $\left(\left.\right|^{\wedge} 2=. \%, p=\right.$.)

Inestimable predictive distribution with $<3$ studies

Yemen

Inestimable predictive distribution with $<3$ studies

Jordan

Inestimable predictive distribution with $<3$ studies

Iraq

Pooled prevelance $\left(\left.\right|^{\wedge} 2=\%, p=\right.$.)

Inestimable predictive distribution with $<3$ studies

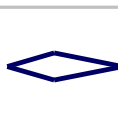

I

$(0.0,0.3)$

$14.4(9.5,20.0)$

$(0.0,0.4)$

$6.6(3.7,10.3)$

$(0.0,0.2)$

$0.4(0.0,2.4)$

$(-,-)$

$\cdot(-,-)$

Oman

Pooled prevelance $\left(1^{\wedge} 2=. \%, p=.\right)$

Inestimable predictive distribution with $<3$ studies

Kuwait

Pooled prevelance $\left(\left.\right|^{\wedge} 2=96.8 \%, p=0.0\right)$

with estimated predictive interval

Morocco

Pooled prevelance $\left(\left.\right|^{\wedge} 2=. \%, p=\right.$

Inestimable predictive distribution with $<3$ studies

Heterogeneity between groups: $p=0.000$

Overall prevelance $\left({ }^{\wedge} 2=99.0 \%, p=0.0\right)$

with estimated predictive interval
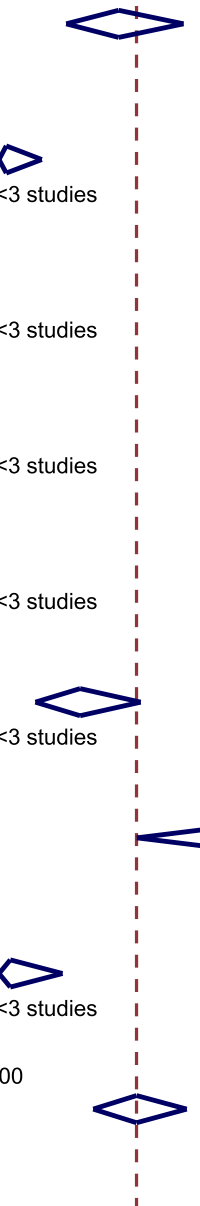

$(-,-)$

$25.5(15.4,37.1)$

$(-,-)$

$4.5(2.0,7.9)$

$(-,-)$

$13.8(7.7,21.4)$

$(0.0,0.6)$

$0.6(0.0,3.5)$

$(-,-)$

$7.6(5.2,10.4)$

$(0.0,0.3)$

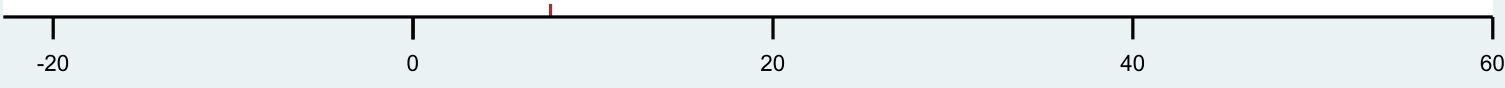

Fig. 3 Forest plot of the meta-analyses for the 10 MENA countries' studies on pre-DM pooled findings of 52 pre-DM prevalence estimates reported in 10 countries in the MENA region. The individual 52 estimates and their $95 \%$ confidence interval (Cl) omitted to fit the plot. The diamond is centered on the summary effect estimate, and the width indicates the corresponding 95\% Cl. UAE, United Arab Emirates; pre-DM, pre-diabetes mellitus; MENA, Middle East and Northern Africa

the comparable burden of T2DM $(7.5 \%, 95 \%$ CI $6.9-9.0 \%)$ and pre-DM (7.6\%, 95\% CI 5.2-10.4\%) in women of childbearing age. The estimated prevalence of T2DM and preDM in 14 countries in the MENA is similar to the estimated worldwide crude diabetes prevalence of $8.2 \%$
(95\% credible interval (CI) 6.6-9.9\%) in adult women in 2014 (age-standardized 7.9\%, 95\% CI 6.4-9.7\%) [91]. The T2DM and pre-DM prevalence in women of childbearing age varied across the three sub-regions in the MENA, by population group, time period, DM ascertainment criteria, 
and sample size. The obvious common prevalence of T2DM and pre-DM in women of childbearing age in the MENA countries reflects the highest prevalence of adult diabetes estimated for the MENA [91]. In this region, the crude diabetes prevalence in adult women increased from $5.0 \%$ in 1980 to $9.0 \%$ in 2014 [91]. This increase in diabetes prevalence among adult populations in the MENA over time is higher than many other regions including Europe and Central and West Africa [91]. The highest national adult diabetes prevalence estimates documented in the MENA is $5-10$ times greater than the lowest national prevalence estimates documented in Western European countries [91].

T2DM is a significant public health problem in both developed and developing countries that can lead to various health complications including increased overall risk of dying prematurely [20]. The common burden of T2DM and pre-DM in women of childbearing age, which is reflected in the high burden of adult diabetes in this region [91], might be mainly driven by the sociodemographic changes in this region. In recent decades, there was an increase in median age, sedentary lifestyle, and physical inactivity in the MENA [92]. These lifestyle changes are linked to an increase in the burden of body overweight and obesity that are shared predisposing factors for pre-DM and T2DM [20]. At the population level, physical inactivity was very common in many MENA countries (Saudi Arabia 67.6\% in 2005; Kuwait 62.6\% in 2014; Qatar 45.9\% in 2012; Egypt 32.1\% in 2011-2012; Iraq $47.0 \%$ in 2015) [25]. The burden of body overweight and obesity is higher in many lowincome and middle-income countries in the MENA than in Europe and Asia Pacific countries [93]. Obesity in women in several Middle Eastern countries was $40-50 \%$ [93]. The age-standardized prevalence of obesity was $32.0 \%$ in Egypt, 35.5\% in Jordan, 30.4\% in Iraq, 32.5\% in Libya, and 35.4\% in Saudi Arabia [94]. In Tunisia, 43.7\% and $24.1 \%$ of $35-70$-year-old females in urban and rural areas, respectively, were obese [95]. In 2016, in almost all of the countries in MENA, the mean BMI for people aged $\geq 18$ years was $\geq 25.0$ [96].

To curb the burden of DM and its associated complications in women of childbearing age in the MENA countries, our results suggest three main implications for care. First, based on the estimated $5-10 \%$ progression rate from pre-DM to T2DM $[3,10]$, out of the 47 , 958 tested women of childbearing age for pre-DM (Table 3), we estimate that 2398 to 4796 women are expected to progress to T2DM. This risk of progression to T2DM could be reduced through lifestyle and drugbased interventions as it was reported elsewhere [9799]. In England, 55-80\% of participants with hyperglycemia at baseline had normal glycaemia at 10 year follow-up [3]. The high burden of DM along with pre-
DM in women of childbearing age could accelerate maternal complications including GDM leading to increased intergenerational risk of DM. Programs to halt the growing epidemic of DM among different population groups could start by addressing the key risk factors including sedentary lifestyle and increased body weight. Addressing this problem would require social and public policies and efforts to reduce the national and regional burden of increased body weight and obesity through enhancing healthy eating behaviors and physical activity. Second, there is a critical need for strengthened surveillance systems that match the scale and nature of the DM epidemic in women of childbearing age in the MENA. Enhancing early detection and management of high-risk individuals requires accessible and affordable health care systems, outreach campaigns to raise public awareness, and social and medical support to induce and maintain a healthy lifestyle. Adult people at increased risk of T2DM and pre-DM can be predicted based on good screening tools from the Centers for Disease Control and Prevention (CDC) [100] and the American Diabetes Association (T2DM Risk Test) [101]. Early screening and detection will require government-funded prevention programs. Third, controlling the burden of T2DM and pre-DM in MENA countries requires strong and successful partnerships between public health and clinical departments. Physicians have a fundamental role in the care of individual patients to screen, diagnose, and treat both pre-DM and T2DM in clinical settings. In addition, physicians have a fundamental role in working to raise awareness and participating in developing prevention programs and engaging communities. Concerted efforts and partnership between physicians, health departments, and community agencies are needed to strengthen health care services, encouraging and facilitating early screening and detection, and promoting healthy diets and physical activity.

Providing summary estimates and up-to-date mapping gaps-in-evidence of T2DM and pre-DM prevalence in women of childbearing age in different MENA countries provides the opportunities for future public health interventions and research to better characterize the T2DM and pre-DM epidemiology nationally and regionally. Nevertheless, present review findings suggest that the DM burden in women of childbearing age in MENA countries is capturing only the tip of the iceberg. Identifying gaps-inevidence through systematically reviewing and summarizing the literature has public health research implications. Our review shows that in many countries, the estimation of the burden of T2DM or pre-DM in women of childbearing age in general populations occurred more than a decade ago (Table 1). Additionally, the review shows that there was no data on the burden of T2DM and pre-DM in women of childbearing age in several countries in the MENA region. This lack of evidence on a key public heath 
outcome requires a strongly resourced research capacity and research funding schemes. There is evidence that federally funded research can impact important health issues that affect a large segment of the population [102].

\section{Strengths}

This robust approach to the literature search and review as well as in retrieving and extracting relevant data from the published literature allowed us to provide summary estimates on the burden of T2DM and pre-DM in women of childbearing age from the 14 and 10 countries in the MENA, respectively. Once the diagnosis was established, regardless of the ascertainment criteria, patients were treated as having diabetes or pre-diabetes. Thus, generating pooled estimates, regardless of the DM ascertainment criteria, stratified according to various population groups, provided more insights into the actual burden of T2DM and pre-DM in various populations of women of childbearing age. The meta-regression analysis identified sources of variations in T2DM and pre-DM prevalence and sources of between-study heterogeneity in prevalence estimates. (Additional files 9 and 11 show these in more detail). The country-stratified and populationstratified T2DM and pre-DM prevalence reports revealed gaps in evidence that can help strengthen research and DM control programs in the most affected countries and populations. The use of probability sampling was very common in the studies included, which may provide broader insights on the representation of our findings to the general or specific group of women of childbearing age at the national, but not at the regional, level.

\section{Limitations}

There are important but unavoidable limitations when interpreting the results of our review. Despite the estimated DM prevalence, the actual DM burden could have been underestimated, at country, sub-regional, or regional level, due to several reasons. The inaccessibility of data on pre-DM or T2DM in women of childbearing age from several countries in the MENA may not necessarily mean an actual lack of data. To meet the aim of our review of estimating the burden of pre-DM and T2DM in women of childbearing age, in several published studies reviewed, women of childbearing age were found to have been combined with those of other age groups or with men. The presented overall pooled estimates, regardless of the tested population group, should not be interpreted as the total burden of the outcome at the population level. Utilizing data on T2DM and pre-DM from only 14 and 10 countries may limit the findings from being generalizable to the entire MENA region. Although we followed a thorough and well-defined search strategy, there is a potential of publication bias as shown in funnel plots (Additional files 3 and 4). The estimated
T2DM and pre-DM prevalence suggest that only the tip of the iceberg was captured. The presented estimates may not be representative of the true prevalence for each population. This underestimation may be particularly true in low-resource settings where necessary resources and capacity in investigating pre-DM at the community level are lacking. The wide array of blood glucose cut-off points and criteria used for T2DM and pre-DM ascertainment also suggests that overestimation and underestimation bias cannot be excluded. Unless estimated from individual population-based studies only, the presented weighted pooled estimates at the country, sub-regional, or regional level should not be interpreted as the burden of the measured outcomes at the population level. Also, the presented pooled estimates according to the two time periods, from 2000 to 2009 and from 2010 to 2018, should not be interpreted as an over-time change in the burden of the measured outcomes. While our meta-analyses revealed substantial heterogeneity across studies, the meta-regression analyses identified the potential sources of between-study heterogeneity within the framework of the present study and the level of detail that can be used in describing these sources (Tables 1 and 2). Thus, much of the variability in T2DM and pre-DM prevalence across studies might remain unexplained.

Despite these potential limitations, our study provided a characterization of the scale of T2DM and pre-DM among women of childbearing age in several MENA countries based on the best available evidence. Data presented in this review can be used to (a) understand the burden of T2DM and pre-DM among a vital population group and to identify at high-risk populations within this specific population group; (b) guide the planning, implementation, and evaluation of programs to prevent and control DM; (c) implement immediate public health actions to prioritize the allocation of public health resources; and (d) formulate research hypotheses and provide a basis for epidemiologic studies. Future research opportunities should prioritize large country-level and multicenter comparable studies, to determine the prevalence of T2DM and pre-DM in various population groups of women of childbearing age. A definitive characterization of the burden of $\mathrm{DM}$ in women of childbearing age at the regional and sub-regional level would require comparable and empirical studies using standardized methodology and comparable DM ascertainment assays.

\section{Conclusions}

In conclusion, women of childbearing age in the MENA region bear an appreciable burden of T2DM and preDM. The estimated burden of T2DM and pre-DM was higher in the Arabian Peninsula and Fertile Crescent countries compared to the rest of the MENA countries identified with prevalence estimates in this review. 
Although both T2DM (7.5\%) and pre-DM (7.6\%) had similar overall estimated prevalence, there is need for a more focused attention on early detection and control by public health authorities to avoid DM-associated pre-gestational, gestational, and post-gestational complications. Countrylevel early DM detection and control programs should consider the key risk factors of DM, mainly the growing burden of body overweight and obesity. Furthermore, facilitating high-quality research and surveillance programs in countries with limited data on DM prevalence and reporting of DM prevalence estimates in women of childbearing age warrant focus.

\section{Supplementary information}

Supplementary information accompanies this paper at https://doi.org/10 1186/s13643-019-1187-1.

\section{Additional file 1. PRISMA checklist.}

Additional file 2. Search strategies for the six databases, from January 1 2000 to July 12, 2018.

Additional file 3 Funnel plots examining small-study effects on the pooled T2DM prevalence among women of childbearing age. Egger's test $p<0.0001$.

Additional file 4 Funnel plots examining small-study effects on the pooled pre-DM prevalence among women of childbearing age. Egger's test $p<0.0001$

Additional file 5. Weighted prevalence of T2DM and pre-DM in childbearing age women in MENA countries according to age group.

Additional file 6. Sub-regional weighted prevalence of T2DM in women of childbearing age according to the tested population, data collection period, T2DM ascertainment, sample size, and overall, in 14 MENA countries.

Additional file 7. Sub-regional weighted prevalence of T2DM (Figure 1) and pre-DM (Figure 2) in women of childbearing age from 2000 to 2009 and from 2010 to 2018. Square represents the estimated prevalence and lines around the square represent the upper and lower limit of the 95\% confidence interval of the prevalence.

Additional file 8. Timeline view of the weighted prevalence of T2DM (Figure 1) and pre-DM (Figure 2) in women of childbearing age, by publication year.

Additional file 9. Univariate and multivariable meta-regression analyses to identify sources of heterogeneity in studies reporting on T2DM prevalence in women of childbearing age by the different measured characteristics.

Additional file 10. Sub-regional weighted prevalence of pre-DM in childbearing age women according to the tested population, data collection period, Pre-DM ascertainment, sample size, and overall, in the four sub regions of the 10 MENA countries.

Additional file 11. Univariate and multivariable meta-regression analyses to identify sources of heterogeneity in studies reporting on pre-DM prevalence in women of childbearing age by the different measured characteristics.

Additional file 12. Quality assessment of the 48 research reports included in the analysis.

\section{Abbreviations}

ADA: American DM association; aOR: Adjusted odds ratio; Cl: Confidence interval; DM: Diabetes mellitus; GDM: Gestational diabetes mellitus; IDF: International Diabetes Mellitus Association; MENA: Middle East and North Africa; MeSH: Medical Subject Headings; NIH: National Heart, Lung, and Blood Institute: PECO: Participants, exposure, comparator, and outcome: PreDM: Pre-diabetes mellitus; PRISMA: Preferred Reporting Items for Systematic
Review and Meta-Analysis; ROB: Risk of bias; T2DM: Type 2 diabetes; UAE: United Arab Emirates; WHO: World Health Organization

\section{Acknowledgments}

Authors are grateful to the Institute of Public Health, College of Medicine and Health Sciences at the United Arab Emirates University for the infrastructure provided.

\section{Authors' contributions}

RHA conceptualized and designed the study. Al, MM, MQ, KA, and FA assessed the eligibility of the retrieved citations in the titles/abstracts and full-text screening phases. RHA, MM, and FA critically assessed the eligible studies and extracted data. RHA analyzed and interpreted the data. RHA drafted the manuscript. All authors critically reviewed the manuscript. RHA read and approved the final manuscript. All authors read and approved the final manuscript.

\section{Funding}

This systematic review was funded by the Summer Undergraduate Research Experience (SURE) PLUS-Grant of the United Arab Emirates University, 2017 (Research grant: 31M348). The funder had no role in the study design, collection, analysis, or interpretation of the data, nor in writing and the decision to submit this article for publication.

\section{Availability of data and materials}

The datasets used and/or analyzed during the current study and its supplementary information files are available from the corresponding author on reasonable request.

\section{Ethics approval and consent to participate}

There are no primary data used in this review. There is no need for any ethical approval or an exemption letter according to the United Arab Emirates University-Human Research Ethics Committee.

\section{Consent for publication}

Not applicable

\section{Competing interests}

The authors declare that they have no competing interests.

\section{Author details}

${ }^{1}$ Institute of Public Health, College of Medicine and Health Sciences, United Arab Emirates University, P.O. Box 15551, Al Ain, United Arab Emirates. ${ }^{2}$ Department of Biology, College of Sciences, United Arab Emirates University, P.O. Box 15551, Al Ain, United Arab Emirates.

Received: 17 March 2019 Accepted: 7 October 2019

Published online: 08 November 2019

\section{References}

1. International Diabetes Federation. IDF Diabetes Atlas, 8th edn. Brussels: International Diabetes Federation, 2017. https://diabetesatlas.org/resources/2 017-atlas.html Accessed 5 Nov 2018.

2. Nathan DM, Davidson MB, DeFronzo RA, Heine RJ, Henry RR, Pratley R, et al. Impaired fasting glucose and impaired glucose tolerance: implications for care. Diabetes Care. 2007;30(3):753-9.

3. Forouhi NG, Luan J, Hennings S, Wareham NJ. Incidence of type 2 diabetes in England and its association with baseline impaired fasting glucose: the Ely study 1990-2000. Diabet Med. 2007:24(2):200-7.

4. Metcalf PA, Baker JR, Scragg RK, Dryson E, Scott AJ, Wild CJ. Microalbuminuria in a middle-aged workforce. Effect of hyperglycemia and ethnicity. Diabetes Care. 1993;16(11):1485-93.

5. Hoehner CM, Greenlund KJ, Rith-Najarian S, Casper ML, McClellan WM. Association of the insulin resistance syndrome and microalbuminuria among nondiabetic native Americans. The inter-tribal Heart project. J Am Soc Nephrol. 2002:13(6):1626-34

6. Gabir MM, Hanson RL, Dabelea D, Imperatore G, Roumain J, Bennett PH, et al. Plasma glucose and prediction of microvascular disease and mortality: evaluation of 1997 American Diabetes Association and 1999 World Health Organization criteria for diagnosis of diabetes. Diabetes Care. 2000;23(8): 1113-8. 
7. Plantinga LC, Crews DC, Coresh J, Miller ER 3rd, Saran R, Yee J, et al. Prevalence of chronic kidney disease in US adults with undiagnosed diabetes or prediabetes. Clin J Am Soc Nephrol. 2010;5(4):673-82.

8. Nguyen $\Pi$ T, Wang JJ, Wong TY. Retinal vascular changes in pre-diabetes and prehypertension: new findings and their research and clinical implications. Diabetes Care. 2007:30(10):2708-15.

9. Wong TY, Klein R, Sharrett AR, Schmidt MI, Pankow JS, Couper DJ, et al. Retinal arteriolar narrowing and risk of diabetes mellitus in middle-aged persons. JAMA. 2002;287(19):2528-33.

10. Barr EL, Zimmet PZ, Welborn TA, Jolley D, Magliano DJ, Dunstan DW, et al. Risk of cardiovascular and all-cause mortality in individuals with diabetes mellitus, impaired fasting glucose, and impaired glucose tolerance: the Australian Diabetes, obesity, and lifestyle study (AusDiab). Circulation. 2007; 116(2):151-7.

11. Brunner EJ, Shipley MJ, Witte DR, Fuller JH, Marmot MG. Relation between blood glucose and coronary mortality over 33 years in the Whitehall study. Diabetes Care. 2006;29(1):26-31.

12. Al-Rifai RH, Pearson F, Critchley JA, Abu-Raddad LJ. Association between diabetes mellitus and active tuberculosis: a systematic review and metaanalysis. PLoS One. 2017;12(11):e0187967. https://doi.org/10.1371/journal. pone.0187967.

13. Lee MR, Huang YP, Kuo YT, Luo CH, Shih YJ, Shu CC, et al. Diabetes mellitus and latent tuberculosis infection: a systematic review and metaanalysis. Clin Infect Dis. 2017;64(6):719-27.

14. Imamura F, O'Connor L, Ye Z, Mursu J, Hayashino Y, Bhupathiraju SN, et al. Consumption of sugar sweetened beverages, artificially sweetened beverages, and fruit juice and incidence of type 2 diabetes: systematic review, meta-analysis, and estimation of population attributable fraction. BMJ. 2015;351:h3576.

15. Ashrafi M, Gosili R, Hosseini R, Arabipoor A, Ahmadi J, Chehrazi M. Risk of gestational diabetes mellitus in patients undergoing assisted reproductive techniques. Eur J Obstet Gynecol Reprod Biol. 2014;176:149-52.

16. InterAct $C$, Romaguera $D$, Norat $T$, Wark PA, Vergnaud AC, Schulze MB, et al. Consumption of sweet beverages and type 2 diabetes incidence in European adults: results from EPIC-InterAct. Diabetologia. 2013;56:1520-30.

17. World Health Organisation. Sexual and reproductive health. 2015. http:// www.who.int/reproductivehealth/topics/infertility/definitions/en/. Accessed 5 Feb 2019.

18. Clausen TD, Mathiesen ER, Hansen T, Pedersen O, Jensen DM, Lauenborg J, et al. High prevalence of type 2 diabetes and pre-diabetes in adult offspring of women with gestational diabetes mellitus or type 1 diabetes: the role of intrauterine hyperglycemia. Diabetes Care. 2008;31(2):340-6.

19. United Nations. Total Population - Both Sexes. World Population Prospects: The; 2015. pp. Revision 2016. https://esa.un.org/unpd/wpp/Download/ Standard/Population/.

20. World Health Organization. Global report on diabetes. 2016. https://apps. who.int/iris/bitstream/handle/10665/204871/9789241565257_eng.pdf; jsessionid=B27DA6B4FB2DCD29CA71FB7C373A17FA? sequence $=1$. Accessed 30 Jan 2019.

21. Ng M, Fleming T, Robinson M, Thomson B, Graetz N, Margono C, et al. Global, regional, and national prevalence of overweight and obesity in children and adults during 1980-2013: a systematic analysis for the global burden of disease study 2013. Lancet. 2014;384:766-81.

22. Galal O. Nutrition-related health patterns in the Middle East. Asia Pac J Clin Nutr. 2003;12(3):337-43 PubMed PMID: 14505998.

23. Ng SW, Zaghloul S, Ali HI, Harrison G, Popkin BM. The prevalence and trends of overweight, obesity and nutrition-related non-communicable diseases in the Arabian Gulf States. Obes Rev. 2011;12(1):1-13.

24. World Health Organization. Health education and promotion. Physical activity. Available at: http://www.emro.who.int/health-education/physicalactivity/background.html. Accessed 15 Jan 2019.

25. Sharara E, Akik C, Ghattas H, Makhlouf OC. Physical inactivity, gender and culture in Arab countries: a systematic assessment of the literature. BMC Public Health. 2018;18(1):639.

26. Bes-Rastrollo M, Martinez-Gonzalez MA, Sanchez-Villegas A, de la Fuente AC, Martinez JA. Association of fiber intake and fruit/vegetable consumption with weight gain in a Mediterranean population. Nutrition. 2006;22(5):504-11.

27. Kelishadi R, Ardalan G, Gheiratmand R, Gouya MM, Razaghi EM, Delavari A, et al. Association of physical activity and dietary behaviours in relation to the body mass index in a national sample of Iranian children and adolescents: CASPIAN study. Bull World Health Organ. 2007;85(1):19-26.
28. Nasreddine L, Mehio-Sibai A, Mrayati M, Adra N, Hwalla N. Adolescent obesity in Syria: prevalence and associated factors. Child Care Health Dev. 2010;36(3):404-13.

29. Al-Rifai RH, Aziz F. Prevalence of type 2 diabetes, prediabetes, and gestational diabetes mellitus in women of childbearing age in Middle East and North Africa, 2000-2017: protocol for two systematic reviews and metaanalyses. Syst Rev. 2018;1:96.

30. Onarheim $\mathrm{KH}$, Iversen $\mathrm{JH}$, Bloom DE. Economic benefits of investing in women's health: a systematic review. PLoS One. 2016;11(3):e0150120.

31. Liberati A, Altman DG, Tetzlaff J, Mulrow C, Gotzsche PC, loannidis JP, et al. The PRISMA statement for reporting systematic reviews and meta-analyses of studies that evaluate health care interventions: explanation and elaboration. PLoS Med. 2009:6(7):e1000100.

32. Moher D, Liberati A, Tetzlaff J, Altman DG, Group P. Preferred reporting items for systematic reviews and meta-analyses: the PRISMA statement. Int Surg. 2010;8(5):336-41.

33. Nyaga VN, Arbyn M, Aerts M. Metaprop: a Stata command to perform metaanalysis of binomial data. Arch Public Health. 2014;72(1):39.

34. Woodruff TJ, Sutton P. The navigation guide systematic review methodology: a rigorous and transparent method for translating environmental health science into better health outcomes. Environ Health Perspect. 2014;122(10):1007-14.

35. http://www.who.int/reproductivehealth/topics/infertility/definitions/en/.

36. The World Bank. World Bank Country and Lending Groups. https:// datahelpdesk.worldbank.org/knowledgebase/articles/906519-world-bankcountry-and-lendinggroups. Accessed 10 Nov 2017.

37. Sterne JA, Egger M. Funnel plots for detecting bias in meta-analysis: guidelines on choice of axis. J Clin Epidemiol. 2001;54(10):1046-55.

38. National Heart, Lung, and blood institute. Quality assessment tool for observational cohort and cross-sectional studies https://www.nhlbi.nih.gov/ health-topics/study-quality-assessment-tools. .

39. Freeman MF, Tukey JW. Transformations related to the angular and the square root. Ann Math Stat. 1950;21(4):607-11.

40. Miller JJ. The inverse of the freeman -Tukey double arcsine transformation. The American Statistician. 1978;32(4):138

41. DerSimonian R, Laird N. Meta-analysis in clinical trials. Control Clin Trials. 1986;7(3):177-88.

42. Borenstein MHL, Higgins JP, Rothstein HR. Introduction to meta-analysis. Chichester: Wiley; 2009.

43. Higgins JP, Altman DG, Gotzsche PC, Juni P, Moher D, Oxman AD, et al. The Cochrane Collaboration's tool for assessing risk of bias in randomised trials. BMJ. 2011;343:d5928.

44. StataCorp. Stata statistical software: release 15. College Station: StataCorp LLC; 2017.

45. Salima T, Mounira K, Nadjia D. Assessment of nutritional status of pregnant women attending the City Tebessa PMI (Algeria). Natl J Physiol Pharm Pharmacol. 2011;1(2):97-105.

46. Eldesoky A-EE, Gad $Y Z$, Ahmed N. Nonalcoholic fatty liver disease in young adult Egyptian women with polycystic ovary syndrome. Egyptian Liver J. 2013:3:15-9

47. Ebrahimi $\mathrm{H}$, Emamian $\mathrm{MH}$, Hashemi $\mathrm{H}$, Fotouhi A. High incidence of diabetes mellitus among a middle-aged population in Iran: a longitudinal study. Can J Diabetes. 2016;40(6):570-5.

48. Valizadeh M, Alavi N, Mazloomzadeh S, Piri Z, Amirmoghadami H. The risk factors and incidence of type 2 diabetes mellitus and metabolic syndrome in women with previous gestational diabetes. Int J Endocrinol Metab. 2015; 13(2):e21696.

49. Hossein-Nezhad A, Mirzaei K, Maghbooli Z, Larijani B. Maternal glycemic status in GDM patients after delivery. Iran J Diabetes Lipid Disorders. 2009;8(1):95-104.

50. Azimi-Nezhad M, Ghayour-Mobarhan M, Safarian M, Esmailee H, Parizadeh SM, Rajabi-Moghadam M, et al. Anthropometric indices of obesity and the prediction of cardiovascular risk factors in an Iranian population. ScientificWorld J. 2009;9:424-30.

51. Azimi-Nezhad M, Ghayour-Mobarhan M, Parizadeh MR, Safarian M, Esmaeili H, Parizadeh SM, et al. Prevalence of type 2 diabetes mellitus in Iran and its relationship with gender, urbanisation, education, marital status and occupation. Singap Med J. 2008;49(7):571-6.

52. Hadaegh F, Bozorgmanesh MR, Ghasemi A, Harati H, Saadat N, Azizi F. High prevalence of undiagnosed diabetes and abnormal glucose tolerance in the Iranian urban population: Tehran Lipid and Glucose Study. BMC Public Health. 2008:8:176 
53. Keshavarz M, Cheung NW, Babaee GR, Moghadam HK, Ajami ME, Shariati M. Gestational diabetes in Iran: incidence, risk factors and pregnancy outcomes. Diabetes Res Clin Pract. 2005;69(3):279-86.

54. Mansour AA, Al-Maliky AA, Kasem B, Jabar A, Mosbeh KA. Prevalence of diagnosed and undiagnosed diabetes mellitus in adults aged 19 years and older in Basrah. Iraq Diabetes Metab Syndr Obes. 2014;7:139-44.

55. Mansour AA, Wanoose HL, Hani I, Abed-Alzahrea A, Wanoose HL. Diabetes screening in Basrah, Iraq: a population-based cross-sectional study. Diabetes Res Clin Pract. 2008;79(1):147-50.

56. Abu-Zaiton A, Al-Fawwaz A. Prevalence of diabetes, obesity, hypertension and associated factors among students of Al-albayt University, Jordan. World J Med Sci. 2013;9(1):49-54.

57. Ahmed F, Waslien C, Al-Sumaie MA, Prakash P, Allafi A. Trends and risk factors of hyperglycemia and diabetes among Kuwaiti adults: National Nutrition Surveillance Data from 2002 to 2009. BMC Public Health. 2013;13:103.

58. Diejomaoh M, Jirous J, Al-Azemi M, Gupta M, Al-Jaber M, Farhat R, et al. Insulin resistance in women with recurrent spontaneous miscarriage of unknown aetiology. Med Princ Pract. 2007;16(2):114-8.

59. Tohme RA, Jurjus AR, Estephan A. The prevalence of hypertension and its association with other cardiovascular disease risk factors in a representative sample of the Lebanese population. J Hum Hypertens. 2005;19(11):861-8.

60. Rguibi M, Belahsen R. Prevalence and associated risk factors of undiagnosed diabetes among adult Moroccan Sahraoui women. Public Health Nutr. 2006; 9(6):722-7.

61. Gowri V, Mathew M, Gravell D, AlFalahi K, Zakwani I, Ganguly SS, et al. Protein Z levels in pregnant Omani women: correlation with pregnancy outcome. J Thromb Thrombolysis. 2011;32(4):453-8.

62. Al-Lawati JA, Al Riyami AM, Mohammed AJ, Jousilahti P. Increasing prevalence of diabetes mellitus in Oman. Diabet Med. 2002;19(11):954-7.

63. Bener A, Zirie M, Janahi IM, Al-Hamaq AO, Musallam M, Wareham NJ. Prevalence of diagnosed and undiagnosed diabetes mellitus and its risk factors in a population-based study of Qatar. Diabetes Res Clin Pract. 2009; 84(1):99-106.

64. Al-Nazhan SA, Alsaeed SA, Al-Attas HA, Dohaithem AJ, Al-Serhan MS, AlMaflehi NS. Prevalence of apical periodontitis and quality of root canal treatment in an adult Saudi population. Saudi Med J. 2017;38(4):413-21.

65. Saeed AAW. Combined systolic diastolic hypertension among adults in Saudi Arabia: prevalence, risk factors and predictors: results of a national survey. Int J Med Res Health Sci. 2017;6(6):171-6.

66. Bahijri SM, Jambi HA, Al Raddadi RM, Ferns G, Tuomilehto J. The prevalence of diabetes and prediabetes in the adult population of Jeddah, Saudi Arabia--A Community-Based Survey. PLoS One. 2016;11(4):e0152559. https:// doi.org/10.1371/journal.pone.0152559.

67. Al-Rubeaan K, Al-Manaa HA, Khoja TA, Ahmad NA, Al-Sharqawi AH, Siddiqui $K$, et al. Epidemiology of abnormal glucose metabolism in a country facing its epidemic: SAUDI-DM study. J Diabetes. 2015;7(5):622-32.

68. Serehi AA, Ahmed AM, Shakeel F, Alkhatani K, El-Bakri NK, Buhari BA, et al. A comparison on the prevalence and outcomes of gestational versus type 2 diabetes mellitus in 1718 Saudi pregnancies. Int J Clin Exp Med. 2015;8(7): 11502-7.

69. Al-Rubeaan K, Al-Manaa HA, Khoja TA, Youssef AM, Al-Sharqawi AH, Siddiqui $K$, et al. A community-based survey for different abnormal glucose metabolism among pregnant women in a random household study (SAUDI-DM). BMJ Open. 2014;4(8):e005906.

70. Amin TT, Al Sultan Al, Mostafa OA, Darwish AA, Al-Naboli MR. Profile of noncommunicable disease risk factors among employees at a Saudi university. Asian Pac J Cancer Prev. 2014;15(18):7897-907.

71. Wahabi HA, Esmaeil SA, Fayed A, Al-Shaikh G, Alzeidan RA. Pre-existing diabetes mellitus and adverse pregnancy outcomes. BMC Res Notes. 2012;5:496.

72. Saeed AA. Association of tobacco products use and diabetes mellitus-results of a national survey among adults in Saudi Arabia. Balkan Med J. 2012;29(3): 247-51. https://doi.org/10.5152/balkanmedj.2012.035

73. Al-Daghri NM, Al-Attas OS, Alokail MS, Alkharfy KM, Yousef M, Sabico SL, et al. Diabetes mellitus type 2 and other chronic non-communicable diseases in the central region, Saudi Arabia (Riyadh cohort 2): a decade of an epidemic. BMC Med. 2011;9:76.

74. Alqurashi KA, Aljabri KS, Bokhari SA. Prevalence of diabetes mellitus in a Saudi community. Ann Saudi Med. 2011;31(1):19-23.

75. Al-Baghli NA, Al-Ghamdi AJ, Al-Turki KA, Al Elq AH, El-Zubaier AG, Bahnassy A. Prevalence of diabetes mellitus and impaired fasting glucose levels in the
Eastern Province of Saudi Arabia: results of a screening campaign. Singap Med J. 2010;51(12):923-30.

76. Al-Qahtani DA, Imtiaz ML, Saad OS, Hussein NM. A comparison of the prevalence of metabolic syndrome in Saudi adult females using two definitions. Metab Syndr Relat Disord. 2006;4(3):204-14.

77. Shaaban LA, Al-Saleh RA, Alwafi BM, Al-Raddadi RM. Associated risk factors with ante-partum intra-uterine fetal death. Saudi Med J. 2006;27(1):76-9 PubMed PMID: 16432598.

78. Habib FA. Incidence of post cesarean section wound infection in a tertiary hospital, Riyadh, Saudi Arabia. Saudi Med J. 2002;23(9):1059-63.

79. Karim A, Ogbeide DO, Siddiqui S, Al-Khalifa IM. Prevalence of diabetes mellitus in a Saudi community. Saudi Med J. 2000;21(5):438-42.

80. Ben Romdhane H, Ben Ali S, Aissi W, Traissac P, Aounallah-Skhiri H, Bougatef $S$, et al. Prevalence of diabetes in Northern African countries: the case of Tunisia. BMC Public Health. 2014;14:86.

81. Sulaiman N, Albadawi S, Abusnana S, Mairghani M, Hussein A, Al Awadi F, et al. High prevalence of diabetes among migrants in the United Arab Emirates using a cross-sectional survey. Sci Rep. 2018;8(1):6862.

82. Shah SM, Ali R, Loney T, Aziz F, ElBarazi I, Al Dhaheri S, et al. Prevalence of Diabetes among migrant women and duration of residence in the United Arab Emirates: a cross sectional study. PLoS One. 2017;12(1):e0169949.

83. Al Dhaheri AS, Mohamad MN, Jarrar AH, Ohuma EO, Ismail LC, Al Meqbaali FT, et al. A cross-sectional study of the prevalence of metabolic syndrome among young female Emirati adults. PLoS One. 2016;11(7):e0159378.

84. Agarwal MM, Dhatt GS, Othman Y. Gestational diabetes mellitus prevalence: effect of the laboratory analytical variation. Diabetes Res Clin Pract. 2015; 109(3):493-9.

85. Hajat C, Harrison O, Al SZ. Weqaya: a population-wide cardiovascular screening program in Abu Dhabi, United Arab Emirates. Am J Public Health. 2012;102(5):909-14.

86. Baynouna LM, Revel AD, Nagelkerke NJ, Jaber TM, Omar AO, Ahmed NM, et al. High prevalence of the cardiovascular risk factors in Al-Ain, United Arab Emirates. An emerging health care priority. Saudi Med J. 2008; 29(8):1173-8.

87. Saadi H, Carruthers SG, Nagelkerke N, Al-Maskari F, Afandi B, Reed R, et al. Prevalence of diabetes mellitus and its complications in a population-based sample in Al Ain, United Arab Emirates. Diabetes Res Clin Pract. 2007; 78(3):369-77.

88. Malik M, Bakir A, Saab BA, King H. Glucose intolerance and associated factors in the multi-ethnic population of the United Arab Emirates: results of a national survey. Diabetes Res Clin Pract. 2005;69(2):188-95.

89. Agarwal MM, Punnose J, Dhatt GS. Gestational diabetes: implications of variation in post-partum follow-up criteria. Eur J Obstet Gynecol Reprod Biol. 2004;113(2):149-53.

90. Gunaid AA, Assabri AM. Prevalence of type 2 diabetes and other cardiovascular risk factors in a semirural area in Yemen. East Mediterr Health J. 2008;14(1):42-56.

91. Collaboration NCDRF. Worldwide trends in diabetes since 1980: a pooled analysis of 751 population-based studies with 4.4 million participants. Lancet. 2016;387(10027):1513-30.

92. Engelhardt H, Schulz F, Büyükkeçeci Z. Demographic and Human Development in the Middle East and North Africa.https://doi.org/10.20378/ irbo-50993. Bamberg: University of Bamberg Press, Universitätsbibliothek Bamberg; 2018. 88 Seiten : Illustrationen, Diagramme p.

93. Collaboration NCDRF. Trends in adult body-mass index in 200 countries from 1975 to 2014: a pooled analysis of 1698 population-based measurement studies with 19.2 million participants. Lancet. 2016; 387(10026):1377-96

94. World health Organization. Global Health Observatory $(\mathrm{GHO})$ data. Overweight and obesity. Noncommunicable diseases. Obesity among adults. 2016. Available at: https://www.who.int/gho/ncd/risk_factors/ overweight_obesity/obesity_adults/en/.1-8 Accessed 10 Dec 2018.

95. El Ati J, Traissac P, Delpeuch F, Aounallah-Skhiri H, Beji C, Eymard-Duvernay $S$, et al. Gender obesity inequities are huge but differ greatly according to environment and socio-economics in a North African setting: a national cross-sectional study in Tunisia. PLoS One. 2012;7(10):e48153.

96. World health Organization. Global Health Observatory $(\mathrm{GHO})$ data. Overweight and obesity. Noncommunicable diseases. Mean body mass index (BMI) trends among adults. Available at https://www.who.int/gho/ ncd/risk_factors/overweight_obesity/bmi_trends_adults/en/ Accessed 10 Dec 2018. 
97. Diabetes Prevention Program Research G, Knowler WC, Fowler SE, Hamman RF, Christophi CA, Hoffman HJ, et al. 10-year follow-up of diabetes incidence and weight loss in the Diabetes Prevention Program Outcomes Study. Lancet. 2009:374(9702):1677-86.

98. Knowler WC, Barrett-Connor E, Fowler SE, Hamman RF, Lachin JM, Walker $E A$, et al. Reduction in the incidence of type 2 diabetes with lifestyle intervention or metformin. N Engl J Med. 2002;346(6):393-403.

99. Ramachandran A, Snehalatha C, Mary S, Mukesh B, Bhaskar AD, Vijay V, et al. The Indian Diabetes Prevention Programme shows that lifestyle modification and metformin prevent type 2 diabetes in Asian Indian subjects with impaired glucose tolerance (IDPP-1). Diabetologia. 2006; 49(2):289-97.

100. Centers for Disease Control and Prevention. National Diabetes Prevention Program. https://www.cdc.gov/diabetes/prevention/index.html Accessed 10 Mar 2019.

101. American Diabetes Association. Type 2 Diabetes Risk Test. http://www. diabetes.org/are-you-at-risk/diabetes-risk-test/?loc=atrisk-slabnav Accessed 2 Mar 2019

102. Drees BM, Yun S. Reducing the burden of diabetes mellitus in the state of Missouri: a call to action. Mo Med. 2016;113(5):352-7.

\section{Publisher's Note}

Springer Nature remains neutral with regard to jurisdictional claims in published maps and institutional affiliations.

Ready to submit your research? Choose BMC and benefit from:

- fast, convenient online submission

- thorough peer review by experienced researchers in your field

- rapid publication on acceptance

- support for research data, including large and complex data types

- gold Open Access which fosters wider collaboration and increased citations

- maximum visibility for your research: over $100 \mathrm{M}$ website views per year

At BMC, research is always in progress.

Learn more biomedcentral.com/submissions 